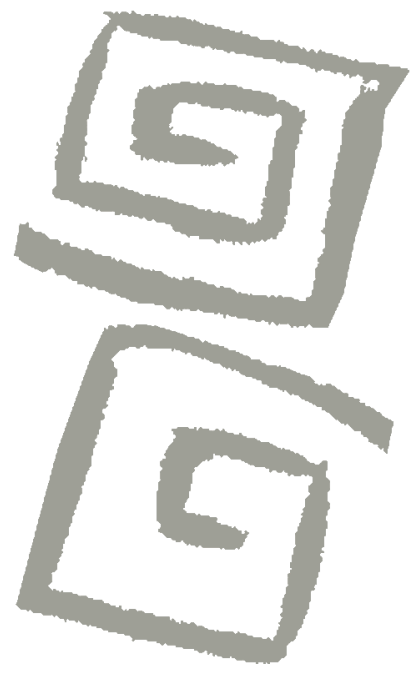

Josep M. Comelles ${ }^{1}$, Isabella Riccò², Aida Terrón Bañuelos ${ }^{3}$, Enrique Perdiguero-Gil ${ }^{4}$

\section{Educación sanitaria y antropología médica en Europa: los casos de Italia y España}

\author{
Health education and medical anthropology in \\ Europe: the cases of Italy and Spain
}

${ }^{1}$ Doctor en Medicina, Doctor en Antropología. Profesor Emérito de Antropología Social, Universitat Rovira i Virgili, Tarragona, España. $\triangle$ (iD)

${ }^{2}$ Magíster en Antropología Cultural y Etnología. Becaria de investigación, Universitat Rovira i Virgili, Tarragona, España.凶 iD

${ }^{3}$ Doctora en Pedagogía. Profesora Titular de Historia y Teoría de la Educación, Universidad de Oviedo, Oviedo, España. $\bowtie$ iD

${ }^{4}$ Doctor en Medicina. Catedrático de Historia de la Ciencia, Universidad Miguel Hernández de Elche, Alicante, España. $\bowtie$ (iD)

RESUMEN El objetivo de este artículo es comparar el desarrollo de la educación sanitaria en Italia y España desde el punto de vista del papel jugado por la antropología médica en ambos países, en un contexto marcado por los cambios en el concepto de educación sanitaria que propugnaron los organismos técnicos de las Naciones Unidas, en especial la Organización Mundial de la Salud y la Unesco, durante la segunda mitad del siglo XX. A pesar de sus similitudes como países, Italia y España tuvieron evoluciones políticas muy diferentes durante el siglo pasado, por tanto, es interesante comparar ambos casos y la influencia que tuvieron las ciencias sociales en las iniciativas de educación sanitaria. Para valorar el papel de la antropología médica, mediante el uso de fuentes orales, hemos reconstruido la puesta en marcha, en 1958, y el desarrollo del Centro Sperimentale per l'Educazione Sanitaria (Perugia, Italia), que estuvo en la vanguardia de la educación sanitaria en Europa hasta los años noventa. Tras una breve descripción de las escasas iniciativas sobre educación sanitaria en la España de la dictadura, evaluamos la influencia de los antropólogos perusinos en la educación para la salud española durante la transición democrática.

PALABRAS CLAVES Antropología Médica; Educación en Salud; Historia del Siglo XX; Italia; España.

ABSTRACT The aim of this article is to compare the development of health education in Italy and Spain from the point of view of the role played by medical anthropology in both countries. The context is provided by the changes in the concept of health education advocated by the UN technical agencies, especially the World Health Organization and Unesco, during the second half of the twentieth century. Despite their many similarities, Italy and Spain underwent different political evolutions over the last century. Therefore, it is interesting to compare both cases and the influence the social sciences had in health education initiatives. In order to assess the role of medical anthropology, the 1958 launch and the development of the Centro Sperimentale per l'Educazione Sanitaria (Perugia, Italy), which was at the forefront of health education in Europe until the 1990s, was reconstructed through oral sources. After a brief description of the scant initiatives regarding health education existing in the Spain of the dictatorship, the influence of the Perusine anthropologists on Spanish health education during the democratic transition is evaluated.

KEY WORDS Anthropology, Medical; Health Education; History, 20th Century; Italy; Spain. 


\section{INTRODUCCIÓN}

La educación sanitaria es una intervención social, que se propone modificar de manera consciente y continua el comportamiento para afrontar los problemas de salud. Esta presupone el conocimiento del patrimonio cultural del grupo y la orientación de sus intereses subjetivos, y requiere la remoción de las resistencias del propio grupo a la intervención. [Traducción del original: L'educazione sanitaria è un intervento sociale, che tende a modificare consapevolmente e durevolmente il comportamento nei confronti dei problemi della salute. Essa presuppone la conoscenza del patrimonio culturale del gruppo discente e la focalizzazione dei suoi interessi soggettivi, e richiede la rimozione delle resistenze opposte dal gruppo stesso all'intervento. Alessandro Seppilli, 1964 $\left.{ }^{(1)}\right]$

En este artículo analizamos la evolución de la educación sanitaria y el papel que jugaron en su desarrollo las ciencias sociales, especialmente, la antropología en Italia y España entre el fin de la II Guerra Mundial y la conferencia de Yakarta sobre promoción de la salud, celebrada en $1997^{(2)}$. En ese periodo la educación sanitaria se desarrolló en torno a unas directrices orientadas a fomentar la participación ciudadana y la de los colectivos sociales, vecinos, trabajadores, minorías étnicas y grupos aborígenes. Tal planteamiento exigía, en ese periodo, una articulación con la sociología empírica y la antropología social y cultural. Italia y España son casos interesantes porque la educación sanitaria tuvo que desarrollarse en contextos políticos que evolucionaron de forma inversa. En Italia se pasó del fascismo, iniciado en 1924, a la democracia, tras el conflicto bélico mundial. En España el régimen democrático fue quebrado por el fascismo en 1936 y no se retornó a la democracia hasta 1977. En Italia, se puso en marcha a finales de la década de los cincuenta el Centro Sperimentale per I'Educazione
Sanitaria (CSES) de la ciudad de Perugia (Italia), una institución de referencia en el desarrollo de la educación sanitaria europea, y activa en el fomento de la participación. Su orientación influyó en las propuestas de educación sanitaria que se llevaron a cabo en España desde los años sesenta, ya finalizado el periodo de aislamiento de la dictadura franquista, y durante la llamada "Transición democrática", que se inicia en 1975 con la muerte del dictador Francisco Franco. Se analiza aquí, a través del recurso a la historia oral, el desarrollo del centro perusino en el contexto de la evolución de la educación sanitaria a nivel mundial, puesto que hasta ahora no existe ninguna historia que permita comprender su evolución. Posteriormente se analiza cómo las propuestas del CSES fueron recuperadas en la España de la Transición democrática, tras el fallido intento de instaurarlas en el sistema educativo español de los años sesenta. Finalmente, se analiza cómo la trayectoria del CSES, entre su fundación y la conferencia de Yakarta, contribuye a explicar la evolución de la agenda internacional sobre este tema.

Una parte sustantiva de este artículo se basa en una serie de entrevistas en audio y algunas en video y un grupo focal realizadas en marzo de 2014 con algunos de los que formaban parte de la generación fundacional del CSES: Maurizio Mori (fallecido en 2016), Maria A. Modolo, Anna Ferrari, Tullio Seppilli y Lamberto Briziarelli.

\section{POPULARIZACIÓN SANITARIA E HIGIENISMO EN ITALIA Y ESPAÑA}

Italia y España, como todos los Estados europeos, desarrollaron estrategias sanitarias -que incluyen la popularización sanitaria y políticas públicas sanitarias-, desde finales del siglo XVIII. A partir de las investigaciones de George Rosen ${ }^{(3)}$, las políticas sanitarias de Francia, el Reino Unido y Alemania han sido utilizadas como referentes de la evolución del "proceso de medicalización". Sin embargo, las pautas de estos países no 
necesariamente se corresponden con lo que ha sucedido en otros países más periféricos, y no es posible extrapolar esas cronologías y modelos de manera automática. Cada Estado moderno tiene especificidades culturales que incluyen la política, el derecho e incluso la economía-, y por ello establecen ajustes de carácter dialéctico con procesos generales tanto en el marco del estado, como a escala regional. Los principales serían la implantación no homogénea ni coetánea del capitalismo, la cronología del desarrollo del constitucionalismo moderno y los efectos de ambos en la secuela cultural, que llamamos "proceso de medicalización" y que incluye acciones de distinto tipo, desde la legislación, a la influencia de los medios de comunicación social, pasando por la práctica cotidiana de los profesionales y las instituciones sanitarias. Su naturaleza "cultural" explicaría su evolución diversa en función de variables estatales, regionales y locales. En la península itálica y en la ibérica -especialmente en España y la Italia unificada-, esa evolución es interesante por las características que comparten ambos países: su complejidad cultural regional, el desarrollo desigual del capitalismo, las variables políticas y los ritmos del despliegue del proceso de medicalización.

España e Italia son, sin embargo, muy distintas. La primera procede de un Estado imperial, que hasta 1714 incluía el sur de la península itálica, Sicilia y Cerdeña. Inicia una lenta transición hacia el constitucionalismo moderno desde 1812 pero no lo consolida hasta finales de la década de 1830 bajo un modelo inspirado en el jacobinismo francés. La Italia unificada, en cambio, es un proyecto de res publica moderno, unión de partes con tradiciones regionales y culturas políticas muy diversas. La Ilustración itálica desarrolló algunas políticas sanitarias singulares en algunos de sus territorios ${ }^{(4)}$, mientras que la medicina social en España no se desarrolló formalmente hasta finales del siglo $X I X^{(5)}$. Ambos países comparten diferencias regionales sustanciales con relación al desarrollo del capitalismo -como el norte de Italia, Cataluña y el País Vasco- junto con regiones subdesarrolladas como la región meridional italiana y el sur de la península ibérica. Comparten, a su vez, que la situación sanitaria de las clases populares y del proletariado campesino a principios del siglo XX eran malas o muy malas según las zonas.

En ambas penínsulas se editaron, desde el siglo XVII un número notable de libros de popularización de la medicina en lenguas vernáculas que ofrecían soluciones prácticas a problemas de salud o eran repertorios de prácticas supersticiosas, erróneas o sobre prejuicios populares que podían aparecer como obstáculos a las "buenas prácticas" basadas en la razón y en el conocimiento médico.

La densidad de médicos en ambas penínsulas era notable a finales del XVIII, por la existencia de la conductio municipal, un contrato de procedencia bajomedieval entre el municipio y el médico, que condujo en Italia a la figura del condotto $^{(4)}$ y que, en España, acabaría convirtiéndose en funcionario público. Sobre el día a día de estos médicos locales recayó el peso de la inculcación de conocimientos de higiene privada y pública, así como una relativa capacidad de influir políticamente a favor de la diseminación de prácticas higiénicas, utilizando, en parte, herramientas etnográficas -topografías médicas e informes médico sociales- para poner de relieve la situación. Durante el siglo XIX fue generalizándose la inclusión de contenidos relacionados con la fisiología y las nociones de higiene en la educación primaria. Finalmente, ambos países emplearon recursos de propaganda de masas, especialmente desde la primera mitad del siglo XX, si bien su estudio pormenorizado solo ha tenido lugar en España ${ }^{(6)}$.

En lo que hace referencia a la diversidad cultural entendida como un obstáculo para la medicalización, los casos de Italia y España, antes de 1945, no siguieron pautas idénticas, a pesar de tratarse de dos estados unitarios. En Italia, el compromiso político de muchos condotti con el nuevo reino, especialmente en las regiones campesinas, les llevó a interesarse por los conocimientos populares relativos a la salud y a la enfermedad ${ }^{(7,8,9,10)}$ y dio lugar al desarrollo del folklore médico ${ }^{(11,12)}$. 
Su interés se consolidó por el valor práctico que adquirió el folklore di guerra ${ }^{(13,14)}$ durante la Primera Guerra Mundial, cuando el reclutamiento puso de relieve la necesidad de gestionar la enorme diversidad cultural y, sobre todo, lingüística, en Italia en el contexto de un estado unitario. Los antropólogos italianos optaron por denominar "demología" a la historia de las tradiciones populares y a la riqueza y diversidad cultural de su demos ${ }^{(15,16)}$, un concepto próximo a la idea de pueblo español que tuvieron también los folkloristas españoles de filiación republicana del siglo $X I X^{(17)}$, que respondía a la necesidad de conocerla y protegerla. Se trataba de una actitud, en ambos casos, distinta de la adoptada por Francia con sus políticas de homogeneización cultural "desde arriba". Antes de la Segunda Guerra Mundial, la teorización por Gramsci del significado del folklore como cultura subalterna $^{(18,19)}$ respondía al debate político y cultural en relación con la diversidad y suponía un reconocimiento, no como una supervivencia del pasado, sino como una realidad dinámica articulada dialécticamente con la Gran Tradición cultural. El reconocimiento del valor de la diversidad cultural no fue negado por el fascismo italiano (19221943), que distingue el popolo cultural y político de su razza biológica:

...un pueblo sano debe poseer una raza sana. La salud del pueblo se vuelve garantía de la raza, porque la victoria del fascismo se da a través de una raza sana. Es interesante, porque el fascismo italiano hace referencia, sobre todo, al mundo de los campesinos, es decir, según Mussolini las virtudes y las habilidades de la raza italiana son aquellas que poseen los campesinos: una manera de trabajar humilde, estable, productiva, que aún preserva las costumbres antiguas y los valores de la raza italiana [traducción del original: ...un popolo sano deve avere una razza sana. La salute popolare diventa una garanzia della razza, perché la vittoria fascista passa attraverso una razza sana ed è interessante perché poi il razzismo italiano fa riferimento al mondo contadino soprattutto, cioè le doti e le virtù della razza italiana sono quelle dei contadini secondo Mussolini, un lavoro continuo, umile, stabile, produttivo, che mantiene solo nel mondo contadino le antiche tradizioni dei valori della razza italiana.

(Seppilli T, 2014, min. 16:05, II)]

La idealización de la vida campesina como crisol de la razza italiana influye en la construcción ideal del campesinado, presente en el fascismo español coetáneo ${ }^{(20)}$ pero no excluye, sino todo lo contrario su articulación con la modernidad:

El lado populista del fascismo lleva a encuestas de salud, vacaciones, corporaciones, en las cuales el sindicato obrero puede dialogar con la patronal y, alguna veces, ganar [...] Durante el fascismo surgen las "mutuas" [instituciones de apoyo] para algunos trabajadores que no tenían cobertura en salud, no todos la teníamos. [Mussolini] ...había creado muchos hospitales, organizado campañas en contra de la malaria y de la tuberculosis. Los hospitales eran públicos y podía haber incluso varios en una provincia, en cambio, hospital psiquiátrico había uno por cada provincia. [Traducción del original: ...il lato populista del fascismo porta a inchieste sanitarie, di vacanza, le corporazioni in cui il sindacato operaio può dialogare con quello padronale e qualche volta vince. [...] Nel fascismo sono nate le mutue con alcune professioni che non erano coperte, non tutti ce l'avevano [...] ha creato molti ospedali, ha fatto campagne soprattutto contro malaria e contro tubercolosi. Gli ospedali sono sempre stati statali potevano essercene anche più di uno in ogni provincia, mentre quelli psichiatrici erano provinciali. (Seppilli T, 2014, min. 39:00, II)

Así, la implantación del seguro de accidentes laborales y de la Cassa nazionale di previdenza per la vecchiaia(4,21,22,23) se 
entienden como agentes de propaganda que buscaban la hegemonía del régimen ${ }^{(24)}$. Se reconoce la influencia del fascismo italiano en el español ${ }^{(20,25,26)}$, tanto en la modernización del campesinado ${ }^{(27)}$, como en el campo sindical-laboral(28), la acción social(29,30) y, sobre todo, con el Seguro Obligatorio de Enfermedad $(\mathrm{SOE})^{(33,36)}$. El fascismo italiano no supuso una ruptura con el Estado -como la dictadura de Primo de Rivera (1924-1930)$y$, del mismo modo, parte de las acciones sociales del fascismo tuvieron continuidad en la Italia republicana de $1947^{(34)}$.

En la España anterior a 1931, salvo algunas acciones sectoriales o regionales, las políticas sanitarias fueron muy modestas por la debilidad económica del Estado(5,34). La II República (1931-1939) hizo un notable esfuerzo para desarrollar la salud pública ${ }^{(36)}$ y una nueva educación primaria obligatoria incluyendo en ella la "higiene escolar" que se mantuvo hasta $1938^{(37)}$. Durante la Guerra Civil, al coexistir zonas bajo el gobierno constitucional, la España franquista se definió como un "Nuevo Estado", inspirado sobre todo por el Novo Estado portugués. Con la derrota republicana, desaparece el Estado tal y como se entendía, y lo sustituye otra entidad, estructurada en torno al partido único Falange Española Tradicionalista de las Juntas de Ofensiva Nacional Sindicalista (FET de las JONS) que se llamaría más tarde, Movimiento Nacional, unión de todos los sectores que habían apoyado el golpe de Estado. Los técnicos sanitarios y los maestros más comprometidos con los ideales republicanos se exiliaron, fueron depurados o subsistieron de distintas maneras. La escolaridad gratuita y obligatoria implantada por la II República no se restableció hasta finales de los años sesenta $^{(37)}$.

La España franquista pretendió aniquilar la diversidad cultural del país e imponer un ideal de España "Por el Imperio hacia Dios" $^{\prime \prime 17,20)}$, basado en un discurso muy centrado en la Gran Tradición y displicente con las "peculiaridades regionales". De ahí que el proyecto del Museo del Pueblo Español, fundado por la República, se detuviera y que los estudios de folklore y etnología se asociaran a los de prehistoria, anclados en la concepción del folklore positivista alemán del siglo XIX. No hubo pues equivalente a los estudios demológicos italianos, sino una marginalidad cultural y académica del folklore ${ }^{(20,25,38)}$.

El franquismo pretendió imponerse sobre las clases populares a partir de la hegemonía cultural, en buena parte, en manos de la Iglesia y de algunos intelectuales orgánicos ${ }^{(20,39)}$ no necesariamente fascistas. Muchos de ellos combinaron la filiación falangista con el pensamiento católico, especialmente, a partir de la derrota de los fascismos en 1945. Este discurso orgánico consideraba el folklore y la diversidad cultural como "costumbrismo" o supervivencias. No fueron cuestiones que tuvieran que tomarse en consideración en las acciones públicas. El folklore médico, que se desarrolla en España impulsado por el italiano en la primera mitad del siglo XX, tenía la misma valoración. En los estudios dedicados a la gestión popular de la salud y la enfermedad se siguió hablando de "supersticiones" que la medicina y la ciencia debían aculturar, como fósiles de un pasado que solo impedían el proceso de medicalización. Las aportaciones al folklore médico presentes en publicaciones periódicas destinadas a médicos se ubican en secciones de humanidades médicas o curiosidades ${ }^{(40)}$. La excepción es el interesante manual Folkmedicina de Antonio Castillo de Lucas destinado también a los galenos ${ }^{(41)}$.

El hecho de que los médicos españoles consideraran el folklore médico como una supervivencia ${ }^{(42)}$ se explica por la hegemonía de una clínica muy organicista, y por la ausencia de la sociología cultural, incompatible con la sociología escolástica oficial, y de la antropología social y cultural, ausente de la universidad hasta la década de 1970. Sin embargo, la bibliografía internacional de este último campo, traducida al castellano en México y Argentina, fue conocida por varios médicos. Otros tantos estuvieron en contacto con esa información en sus idiomas originales. Sin embargo, el relativismo de las ciencias sociales empíricas entraba en contradicción con los presupuestos ideológicos 
de la cultura franquista y del nacionalcatolicismo y no encajaba con los esquemas que manejaban los clínicos, que prácticamente no se hicieron eco de los desarrollos internacionales en las ciencias sociomédicas ${ }^{(43)}$. Son disciplinas que se ubicaban en el dominio de las "humanidades" que un médico culto debía eventualmente conocer sin que tuviesen ninguna traducción práctica ante la hegemonía de una medicina "de enfermedad", básicamente asistencial. Era la que el régimen avalaba como instrumento de propaganda social, para tratar de conseguir la adhesión de las masas. Por ello puede considerarse que, en la España franquista, como en la Italia fascista "el poder solo en parte es coerción, solo en parte es violencia; ningún poder se mantiene si no tiene un lado de hegemonía" [Traducido del original: "il potere è solo in parte coercizione, solo in parte violenza, nessun potere si mantiene se non ha un lato di egemonia" (Seppilli T, 2014, I)].

Los escritos de Antonio Gramsci sobre el folklore ${ }^{(19)}$, el papel de los intelectuales $\operatorname{orgánicos}^{(18)}$, la questione meridionale ${ }^{(44)}$ y su consideración de las culturas campesinas subalternas como el producto de articulaciones y transacciones enlazaban -a pesar de la distancia teórica entre el marxismo y el estructural funcionalismo anglosajón- con un esfuerzo por comprender y dar valor al conocimiento popular $y$, a partir de ello, abrir cauces de comunicación de gran calado en el ámbito de la educación sanitaria. Esto permitiría, desde 1945, un diálogo entre la antropología marxista italiana, la antropología cultural anglosajona y los sanitaristas comprometidos con los nuevos proyectos de educación sanitaria. En cambio, en España, la incompatibilidad de los ideólogos del régimen con el marxismo y el relativismo cultural, así como la consideración del conocimiento popular como "supervivencias", tan solo válidas entre gente ignorante, impediría ese diálogo. Veámoslo por partes. En primer lugar, describiremos someramente el panorama global de la educación sanitaria hasta la conferencia de Yakarta. En segundo lugar, abordaremos el caso italiano para continuar con el de España.

\section{De la Conferencia de San Francisco (1945) a la de Yakarta (1997): la hegemonía global de la participación local en salud}

Entre 1945 y la conferencia de la Organización Mundial de la Salud (OMS) en Yakarta $1997^{(2)}$-pero con la participación de la Food and Agriculture Organization (FAO), Unesco y Unicef en sus respectivos ámbitos de competencia- se desarrolló la idea de una nueva "cultura de la salud" basada en un discurso sobre la participación social a escala local, decisiva en el campo de la educación y, más tarde, de la promoción de la salud, para que se desplegara capilarmente en el ámbito rural, en los barrios, en lo laboral, y como dispositivo escolar ${ }^{(45)}$. Italia se incorporó inmediatamente a este proceso ${ }^{(4)}$, mientras que España, a pesar de sus esfuerzos por disimularlo, tardaría una década en hacerlo por su aislamiento internacional derivado de su perfil político fascista. La España franquista siguió siendo un socio internacional incómodo. Muchas recomendaciones internacionales no llegaron a la ciudadanía por su incompatibilidad ideológica con el régimen.

Este periodo se caracterizó, también, por el creciente papel de los medios de comunicación de masas. Inicialmente prevaleció lo escrito (prensa y revistas) ${ }^{(49)}$, pero rápidamente tuvo un gran papel la radio $y$, desde la década de 1960, la televisión ${ }^{(50)}$.

En 1951 se fundó la Union Internationale pour l'Education Sanitaire de la Population (UIESP) ${ }^{(51)}$, como consecuencia:

...del encuentro entre personas de distintas procedencias: un americano, una rusa, un italiano (Canapera) y un francés que regresaba de África. Un grupo de sujetos no definidos políticamente, pero inspirados en la reconstrucción posterior a la guerra [Segunda Guerra Mundial]. Esto fue lo que llevó a estos personajes a crear esta unión internacional. Era un sentimiento popular en contra de los desastres de la guerra y de las dictaduras. El mundo anglosajón que había derrotado a Alemania y a Japón, de la 
mano de la victoria, fue investido de una idea de libertad que más tarde terminaría cuando, con la Guerra Fría, se quebró todo. Pero en el momento de los acuerdos de Yalta y justo después, bajo el impulso del gobierno laborista inglés que fue clave, Churchill ganó la guerra, pero perdió las elecciones. El partido laborista toma el poder, con Beveridge que diseña el plan. Y ahí se da esta historia, este grupo de personas internacional que funda en la OMS la UIESP por la liberación de la personas en la salud. [Traducido del original: ...dall'incontro fra persone di diversa natura: un americano, una russa, un italiano (Canapera) e un francese che tornava dall'Africa. Un gruppo di soggetti non politicamente definiti, ma ispirati alla ricostruzione del dopo guerra. Questo fu quello che spinse questi personaggi a creare questa unione internazionale. Era un sentimento popolare contro i disastri della guerra e delle dittature. II mondo anglosassone che aveva sconfitto la Germania e il Giappone, sulla scia della vittoria, fu investito da un'idea di libertà, che poi finirà quando, con la Guerra Fredda, si rompe tutto. Ma al momento degli accordi di Yalta e subito dopo sulla spinta del governo laburista inglese che fu la chiave di volta, Churchill vince la guerra ma perde le elezioni. E il partito laburista prende il governo, con Beveridge che fa il piano. E lì c'è questa storia, questo gruppo di persone internazionali che presso l'OMS fonda la UIESP per la liberazione delle persone sulla salute. (Briziarelli L, 2014, min. 23:54)]

El papel de la UIESP y sus congresos fue muy relevante durante casi medio siglo. En buena parte por la persistencia del compromiso profesional de sus miembros con una tarea específica a favor de un modelo de educación sanitaria que tratara de establecer criterios de horizontalidad, frente a los modelos jerárquicos basados en la imposición. Asimismo, se enfatizó la búsqueda de compromisos con los agentes sociales locales a partir de una filosofía -si se nos permite la expresión- participativa. Estas ideas coinciden en el tiempo con la difusión de las metodologías de "intervención-acción participativa", así como con las experiencias de las Ilamadas "comunidades terapéuticas" en salud mental. Como indica Briziarelli, en su relato, se trata de una confluencia característica en un periodo de reconstrucción democrática radical tras la derrota de los fascismos, que coincide, también, con los inicios del despliegue masivo de los estados del bienestar europeos. Corresponde, asimismo, con la amplia hegemonía de la socialdemocracia y la democracia cristiana en Europa.

El objetivo de la educación sanitaria, tal y como entonces se concebía, era avanzar hacia el empowerment de la ciudadanía a partir de un trabajo local, transversal y atento a la diversidad cultural, para la cual contaban con los etnógrafos y científicos sociales ${ }^{(52)}$, y que estaba coordinado por la OMS y sus oficinas regionales, la FAO, para el caso de la alimentación, y la Unicef y la Unesco, para la educación ${ }^{(53)}$. En este último ámbito se procedió a sustituir el viejo concepto de "higiene escolar" por el de "educación sanitaria escolar". Para ello se requería a las administraciones una adaptación educativa y sanitaria que respetara las actitudes y conocimientos locales a partir del registro etnográfico e historiográfico. Esto era cada vez más habitual en América ${ }^{(54,55,56,57)}$, pero no en Europa, por la ausencia de antropología profesional aplicada ${ }^{(46,58,59)}$.

La Conferencia de la OMS ${ }^{(60)}$ en Alma-Ata, en 1978, formalizó el papel capilar de la atención primaria, pero fue la Conferencia de Ottawa de $1986^{(61)}$, la que incorporó la agenda de la promoción y educación para la salud que se venía desarrollando en el último cuarto de siglo y que se basaba en construir una política pública saludable, crear entornos que apoyaran la salud, fortalecer la acción comunitaria, desarrollar habilidades personales y reorientar los servicios de salud. Una década más tarde, en Yakarta, esa hoja de ruta fue revisada: 
Los enfoques globales para el desarrollo de la salud son los más efectivos. Los que usan combinaciones de las cinco estrategias [de Ottawa] son más efectivos que los enfoques de vía única. Ciertos lugares (escenarios) ofrecen oportunidades prácticas para la implementación de extensas estrategias. Estos incluyen megaciudades, islas, ciudades, municipios y comunidades locales, sus mercados, escuelas, sitios de trabajo e instalaciones de cuidados de salud. La participación es esencial para mantener los esfuerzos. La gente debe estar en el centro de las acciones de promoción de la salud y los procesos de toma de decisión para hacerlas efectivas. Aprender acerca de la salud fomenta la participación. El acceso a la información y educación es esencial para lograr la participación efectiva y el empoderamiento de las personas y la comunidad. ${ }^{(2)}$

En la práctica, Yakarta supuso un cambio de rumbo sustantivo ${ }^{(62)}$, con menor énfasis en lo local y más en la responsabilidad individual y en el papel de la comunicación y los medios, que tendría consecuencias, en Italia y en España.

\section{El Centro Sperimentale de Perugia y la educación sanitaria en la Italia democrática}

Las singularidades del centro eran dos: la primera era que la educación sanitaria estaba fuertemente ligada a los servicios, que no era simplemente una actividad de buena voluntad, en particular al servicio educativo y sanitario. La segunda es que trabajar para la educación sanitaria significaba trabajar implícitamente para la reforma sanitaria, para un nuevo sistema de salud. [Traducido del original: Le singolarità del centro erano due: la prima è che l'educazione sanitaria è fortemente legata ai servizi, non è una attività di buona volontà, in particolare al servizio scolastico e sanitario. La seconda è che lavorare per l'educazione sanitaria significava implicitamente lavorare per la riforma sanitaria, per un nuovo sistema sanitario. (Mori M, 2014, min. 04:00)]

La publicación en 1945, de Cristo si è fermato a Eboli del médico Carlo Levi(63) y de La questione meridionale de Gramsci ${ }^{(44)}$ situaron a la cultura popular en la agenda de la Repubblica Italiana, en parte, de la mano del Secretario general del Partido Comunista Italiano (PCI), Palmiro Togliatti:

...bajo el impulso de la OMS y de los movimientos de izquierda, después de la guerra, el Comitato di Liberazione Nazionale in Alta Italia presenta una primera propuesta de servicio nacional de salud, justo después del plan Beveridge. A partir de en un proyecto del Convegno San Pellegrino surge un primer borrador del Servizio Sanitario Nazionale, en el cual se prevé la participación de la gente. [Traducido del original: ...sotto le spinte dell'OMS e dei movimenti di sinistra subito dopo la guerra, il Comitato di Liberazione Nazionale in Alta Italia, formula una prima proposta di servizio sanitario nazionale, subito dopo il piano Beveridge. E poi in un progetto del Convegno San Pellegrino emerge una prima linea d'idea di Servizio Sanitario Nazionale, in cui c'è dentro l'idea della partecipazione della gente. (Briziarelli L, 2014, min. 03:11)]

La propuesta de la izquierda italiana, iba asociada a una proyecto de largo recorrido en el que tendría un papel muy relevante Ernesto de Martino (1908-1965), un antropólogo e historiador de la religión, entonces miembro del $\mathrm{PCl}$ y uno de los intelectuales italianos de referencia. Según Seppilli, camarada y discípulo del anterior:

Había empezado la polémica en Società, la revista teórica del partido [Partido Comunista Italiano], sobre el significado de las clases subalternas, de la cultura 
popular. Construimos juntos esta primera estructura tentativa de antropología marxista en Italia, que luego llevó, desde un punto de vista empírico, a la gran investigación de De Martino. [Traducido del original: Era cominciata la polemica su Società, sulla rivista teorica del partito [PCI], sul significato delle classi subalterne, della cultura popolare, costruimmo insieme questa prima struttura di un tentativo di antropologia marxista in Italia che poi portò, da un punto di vista empirico, alla grande ricerca di de Martino. (Seppilli T, 2014, min. 23:33, I)]

Poco antes, en 1948, se había publicado la Medicina popolare in Italia de Pazzini(64) e II mondo magico por De Martino(65,66). Si Pazzini aun acepta la magia como "pretécnica", el segundo la considera una práctica social y de resistencia y no de supervivencia, algo así como un bricolage necesario para lo cotidiano. Conocerla era indispensable para comprender la cultura local e implantar estrategias de medicalización que aceptasen su eficacia:

Trabajar el tema de la medicina popular resultaba un poco general, teníamos que definir qué clase social y en qué condiciones. Surgió un campo de investigación que tenía raíces en el siglo XIX, pero se estaba desarrollando en una nueva dirección, porque nosotros estábamos trabajando en el supuesto de que la medicina popular no era superstición, sino que tenía base empírica. La ritualidad se tornaba parte de la eficacia. [Traducción del original: Lavorare all'idea della medicina popolare era un po' generico, bisogna vedere quali classi sociali in quali condizioni. Venne avanti un settore di ricerche che aveva le radici nell'ottocento, ma andava sviluppandosi in una nuova direzione, perché noi lavoravamo nell'ipotesi che la medicina popolare non fosse superstizione, avesse delle basi empiriche. La ritualità era una parte dell'efficacia. (Seppilli T, 2014, min. 35:06, I)]
Por eso en La terra del rimorso, De Martino incorporó trabajadores sociales y psiquiatras $^{(67)}$, algo excepcional en Europa. La nueva Repubblica quería resolver el problema del acceso a los servicios sanitarios de la ciudadanía, especialmente de los grupos subalternos:

En 1951, en Londres, hubo un encuentro internacional centrado en los países de la posguerra. En este congreso participó el médico de la provincia de Perugia. En el encuentro se estableció que se podían construir centros de educación sanitaria en los distintos países. En Italia se fundaron uno en Milán (que duró pocos años) y uno en Perugia [...] que encontró un entorno favorable porque en el Instituto de Higiene de la Universidad de Perugia estaba Alessandro Seppilli [...] La intención era que se incorporara a la universidad y a las entidades locales (comisarías, provincias, regiones) [Traducción del original: Nel 1951 a Londra ci fu un incontro internazionale con attenzione ai paesi post guerra. A questo convegno partecipò il medico provinciale di Perugia. In questo incontro si stabilì che si potevano costituire dei centri di educazione sanitaria nei vari paesi. In Italia se ne fondò uno a Milano (durato pochi anni) e uno a Perugia [...] che trovò ambiente favorevole perché all'Istituto d'Igiene dell'Università di Perugia, c'era Alessandro Seppilli. [...] L'intenzione era quella di avere dentro I'università e gli enti locali (comuni, provincia, regione).

(Modolo MA, 2014, min. 17:00)]

En la práctica, el modelo italiano de educación sanitaria se basaría en las dos décadas siguientes en dos instituciones: una localizada en Milán, que se orientó, sobre todo, "a la comunicación social, radio y carteles" (Briziarelli L, 2014 min. 14:00); mientras que el de Perugia asumió un papel distinto, puesto que se basó en la concertación con las autoridades locales de izquierda: 
...siguiendo las indicaciones internacionales de la III Conferencia Mundial de Educación Sanitaria de Roma (1954), junto con el médico de la provincia de Perugia, con el soporte de Carlo Alberto Canaperia, Director General del Ministerio en Roma [...] Canaperia creó el Consejo Italiano ES [educación sanitaria] del cual [Alessandro] Seppilli era una de las personas más importantes. El presidente era el profesor romano Papaldo. Se limitaba a trabajar la ES con mensajes a través de la radio, de los diarios, de carteles, pero no había un proyecto. La diferencia que introdujo Seppilli desde el principio fue la de hacer un gran esfuerzo formativo del personal para esta función específica, adoptando modelos centrados en la gente, una aproximación directa a la población, trabajando con la gente a través del contacto con los médicos de base, con las parteras, con los enfermeros, en este modelo que se convertiría en el modelo del CSES, pero que no encontraba gran consenso en el resto del país. El modelo del centro era distinto al modelo del Centro de Educación de la Población de Milán. En Perugia la elección fue utilizar medios de comunicación bidireccionales y buscar el contacto con la gente. Esta era la gran diferencia que caracterizaba a nuestro modelo y que empezaba a delinearse bajo la dirección de Modolo, Maurizio Mori, Ferrari y otros. Nuestro compromiso fue crear un modelo de formación de los profesionales que fuese transferible en un vínculo bidireccional con la gente, de trabajo en grupo, con la discusión grupal como instrumento. [Traducción del original: ...sulla scorta delle indicazioni internazionali della III Conferenza Mondiale di Educazione Sanitaria a Roma (1954), insieme al medico provinciale di Perugia, con l'influsso di Carlo Alberto Canaperia, Direttore Generale al Ministero a Roma [...] Canaperia aveva creato il Comitato Italiano di ES (Educazione Sanitaria) di cui [Alessandro] Seppilli era una delle persone importanti, il presidente era un Prof. romano Papaldo, però si limitavano a ragionare di ES con messaggi attraverso radio, giornali, manifesti, a mandare in giro segnali, ma non c'era un progetto. La differenza che introduce Seppilli da subito fu quella di fare un grosso sforzo formativo del personale per questa specifica funzione, adottando modelli di approccio nei confronti della gente, un approccio diretto con la popolazione, lavoro con la gente attraverso il contatto con i medici di base, con le ostetriche, con gli infermieri, in questo modello che diventerà il modello del CSES che però non trovavano nel resto del paese un grande consenso. Il modello del centro era diverso dal modello del Centro di Educazione della Popolazione a Milano. A Perugia la scelta era quella di utilizzare mezzi di comunicazione bidirezionale e cercare il contatto con la gente. Questa era la grande differenza che caratterizzava il nostro modello che cominciava a delinearsi sotto la direzione della Modolo, Maurizio Mori, Ferrari e altri. Il nostro impegno fu quello di creare un modello di formazioni degli operatori che fosse trasferibile nei rapporti con la gente di tipo bidirezionale, lavoro di gruppo, discussione di gruppo come strumento. (Briziarelli L, 2014, min. 12:39)]

Milán y Perugia representan dos estrategias complementarias, presentes en el desarrollo de la educación sanitaria internacional. Optar por una o por otra dependía, a menudo, del perfil de los fundadores y de su compromiso social, sanitario y político. En el caso perusino, la iniciativa partió del salubrista Alessandro Seppilli (1902-1995):

Él hablaba alemán, nació bajo el gobierno austro-húngaro, estudió alemán para el examen de fisiología, era de cultura germánica y en su manera de ser era un austríaco, rígido en los horarios, en el trabajo y en la forma. Era un liberal y se volvió socialista cuando regresó a 
Italia. Era un liberal incluso en el espíritu. Estuve muy cerca de él, viajamos juntos, fuimos al extranjero, estaba muy interesado por los problemas sociales, pero como formación política era más cercano a los liberales que a los socialistas. Era un libertario, un liberal en el sentido del siglo XIX del término, pero tenía gran apertura mental y respetaba las opiniones de los demás. Era aristocrático y tomaba poco en cuenta a los ignorantes, no a los pobres, sino a la gente estúpida; pero todos los que tenían cosas importantes que decir, había que escucharlos, y esta era la razón por la cual estaba abierto a las opiniones, a la discusión. [...] De antigua tradición higienista, en los años cincuenta hace una apertura de naturaleza política hacia la parte social de la medicina y de la higiene, bajo el impulso de las innovaciones que venían del mundo internacional de la OMS y de los movimientos de izquierda que agitaban la nación después de la guerra. Seppilli, mientras fue alcalde de Perugia, socialista, absorbió estos elementos de tipo cultural y los incorporó dentro del Instituto de Higiene como forma de enseñanza para los estudiantes, como desafío paralelo dentro del Instituto de Higiene para desarrollar acciones educativas y también de investigación. Inicialmente solo de tipo educativo [...] Seppilli le interesaba sobre todo el CSES, desplazando la higiene tradicional hacia nuevas fronteras: educación sanitaria, promoción de la salud, epidemiología, ambiente, prevención, una higiene, sobre todo, técnica. [Traducido del original: Lui parlava tedesco, era nato sotto I'indirizzo austro-ungarico, aveva studiato tedesco per fare l'esame di fisiologia, era di cultura mitteleuropea e nella sua impostazione ordinaria era un austriaco, rigido negli orari, nel lavoro, nella forma. Era un liberale e diventò socialista quando tornò in Italia. Era un liberale anche nello spirito. Io gli sono stato molto vicino, abbiamo viaggiato insieme, siamo andati all'estero, lui era apertissimo ai problemi sociali, ma come formazione politica era più vicino ai liberali che non ai socialisti. Era un libertario, un liberale nel senso ottocentesco del termine, però aveva una grande apertura mentale rispetto alle opinioni degli altri. Era aristocratico e considerava poco gli ignoranti, non i poveri, ma la gente stupida, però tutti coloro che avevano cose importanti da dire, bisognava ascoltarli e questa era la ragione per la quale era aperto alle opinioni, al confronto. [...] Di antica tradizioni igienista, fa negli anni cinquanta una apertura di natura politica verso la parte sociale della medicina e dell'igiene, sotto la spinta delle innovazioni che venivano dal mondo internazionale della OMS dei movimenti di sinistra che agitavano la nazione dopo la guerra. Seppilli che intanto era sindaco di Perugia, socialista, recepisce questi elementi di tipo culturale e li inserisce sia dentro I'lstituto d'Igiene come forma de insegnamento per gli studenti sia come impresa parallela all'interno dell'Istituto d'Igiene per svolgere azioni di tipo educativo e anche di ricerca. Inizialmente solo di tipo educativo. [...] Seppilli dedicava la sua attenzione soprattutto al CSES, spostando l'igiene tradizionale verso nuove frontiere: educazione sanitaria, promozione della salute ed epidemiologia, ambiente, prevenzione, una igiene che era soprattutto tecnica. (Briziarelli L, 2014, min. 29:00)]

Alessandro Seppilli nacido en Trieste (Imperio Austro Húngaro) en 1902, de origen judío, fue un personaje carismático hasta su muerte en Perugia, en 1995, por su proyección científica, académica y política. Casado con la antropóloga Anita Schwarzkopf, esta contribuyó a su interés por:

Acercarse a la comprensión de las diversidades, a educar con mucha cordialidad el intercambio con diversas profesiones, para que los demás entendieran que la educación sanitaria 
implicaba relacionarse incluso con personas distintas, tal era la clausura que había en Italia. Había una cultura aún muy conectada con el poder profesional. [Traducción del original: ...cercava di avvicinarsi alla comprensione delle diversità, di educare con molta dolcezza $i$ rapporti con diverse professioni, cercando di far capire che l'educazione sanitaria comportava la relazione anche con persone diverse, c'era una tale chiusura in Italia. C'era una cultura ancora molto collegata al potere della professione. (Ferrari A, 2014, min. 34:00)]

La actitud que Alessandro Seppilli se construyó a partir de su experiencia académica y como técnico salubrista, antes de su exilio en Brasil, y por la experiencia en el trato humano que adquirió en el exilio como director de una industria farmacéutica. No cabe duda que, a su regreso a Italia y en el proyecto del CSES, su capacidad para gestionar un equipo de jóvenes fue una de las claves del desarrollo de la institución. Así lo cuenta uno de ellos:

Llegué a Perugia en 1954, después de graduarme en medicina. Empecé a asistir al curso de higiene en quinto y sexto año. Me contacté con el profesor Seppilli por una tesis. Una vez recibida, Seppilli me dijo que podía trabajar en educación sanitaria y me fui al (a ver el) médico provincial. [...] La OMS otorgaba una beca para ir a Londres, la gané y me fui a Londres al Health Education Center of London. Estuve un año allí. Me Ilamaba mucho la atención que se trabajaba mucho en grupo. En el 57 regresé y decidimos difundir esto de la educación sanitaria entre los profesionales de la salud, decidimos organizar un curso de verano, porque en Londres organizaban un curso de verano para los profesionales de los servicios de salud. Un año después lanzamos el curso, la OMS nos apoyó invitando a mi tutor de Londres, John Burton, que hablaba italiano porque se había casado con una italiana. [Traducción del original: lo venni a Perugia nel 1954, dopo che mi laureai in medicina. Cominciai a frequentare il corso d'igiene, quinto e sesto anno. Contattai il prof. Seppilli per una tesi. Una volta laureata, Seppilli mi disse che potevo occuparmi di educazione sanitaria e andai dal medico provinciale.[...] L'OMS aveva dato una borsa di studio per Londra, la presi io e andai a Londra, al Health Education Center of London. Feci un anno lì. La cosa che mi aveva colpito molto era che si lavorava molto in gruppo. Nel '57 io tornai e si decise di diffondere questa storia dell'educazione sanitaria tra operatori sanitari e scolastici e si decise di fare il corso estivo, perché a Londra facevano un corso estivo per personale dei servizi. L'anno dopo lanciammo il corso, la OMS ci aiutò mandandoci il mio tutor di Londra, John Burton, che parlava italiano perché aveva sposato una italiana. (Modolo MA, 2014, min. 21:00)]

La combinación entre el pragmatismo británico de Burton y el compromiso social de la izquierda italiana de los cincuenta permitieron la incorporación de:

...ideas muy abiertas y la apertura a todo un modelo de ES [educación sanitaria] que no conocíamos aquí, salvo el que se estaba construyendo en Perugia. Comenzamos de inmediato a interactuar con la gente tanto porque Seppilli nos impulsaba en esa dirección, como porque en los años sesenta la sanidad había empezado una lucha contra las enfermedades sociales, entonces se hacían intervenciones contra la tuberculosis, el tracoma, la rabia y empezaban las acciones para prevenir el cáncer cervicouterino. Empezamos a hacer propaganda, lo cual no era propio de la ES, porque íbamos a los pueblos, en la noche proyectábamos películas y después explicábamos cómo se tenía que hacer para la detección del cáncer. 
[Traducción del original: ...idee molto aperte e aprí tutto un modello di ES che non conoscevamo qui, salvo quello che si stava costruendo qui in Perugia. Cominciammo subito un'azione con la gente perché sia per Seppilli che spingeva in questa direzione sia perché negli anni '60 la sanità aveva avviato una lotta contro le malattie sociali, quindi c'erano interventi contro la tubercolosi, il tracoma, la rabbia e cominciavano gli interventi per la prevenzione dei tumori della cervice uterina. Cominciammo a fare propaganda che non era proprio $E S$, perché andavamo nei paesini, la sera proiettavamo una pellicola e dopo spiegavamo come si doveva fare per lo screening del cancro. (Briziarelli L, 2014, $\min$. 09:00)]

No cabe duda de que el modelo italiano, que incorporaría rápidamente el discurso de la antropología crítica marxista, reticente ante el estructural funcionalismo anglosajón de esa época ${ }^{(46)}$, contribuyó a la identidad del CSES:

...con el modelo anglosajón teníamos una relación de amor y odio, porque recibíamos mucho de la cultura que se formaba a nivel europeo, sobre todo de la parte inglesa laborista, pero no mucho desde la parte americana. Entonces tuvimos siempre contacto e inspiración de alguna parte de científicos británicos, y mucho menos de los estadounidenses. En cambio, teníamos una estrecha relación intelectual con canadienses, que tenían modelos avanzados similares a los nuestros, y con algunos holandeses y alemanes, cercanos a los movimientos socialdemócratas. A través de la UISEP teníamos dos tipos de actitudes. Uno: desarrollamos un modelo italiano de corte socialdemócrata que avanzó en plena reforma sanitaria y con la participación de la población, pero los elementos culturales de información y educación sanitaria eran aquellos que venían de los lugares como el norte de
Europa. Se trataba de una relación de amor y odio porque nosotros combatíamos como militantes de izquierda, la influencia estadounidense, e incluso la del gobierno inglés, pero el espíritu cultural de las vanguardias culturales que venían de Inglaterra eran como el nuestro, trabajábamos juntos en esto. El Bundeszentrale für gesundheitliche Aufklärung de Colonia era cercano a nosotros porque estaba dirigido por científicos cercanos al SPD, que era algo raro y difícil a encontrar en la UIESP porque nunca había hablado de educación sanitaria sobre los problemas de salud de los trabajadores, y eso se le dejaban todo a la OIT de Ginebra. [Traducción del original: ...avevamo con il modello anglosassone un rapporto di amore e odio perché noi recepivamo moltissimo dalla cultura che si formava a livello europeo, soprattutto dalla parte inglese laburista, non dalla parte americana. Quindi avemmo sempre un contatto e un'inspirazione da alcune parti degli scienziati inglesi, molto meno dagli americani e invece avemmo stretti rapporti intellettuali con i canadesi che avevano dei modelli avanzati vicino ai nostri e con quella parte di olandesi e tedeschi che erano tutti vicini ai movimenti socialdemocratici. Attraverso I'UISEP noi avevamo due tipi di atteggiamenti. Uno: sviluppavamo un modello italiano di tipo socialdemocratico avanzato sul pieno della riforma sanitaria e della partecipazione della gente, ma gli elementi culturali di informazione di educazione sanitaria erano quelli che venivano dalle punte avanzate di tipo Nord Europeo. Era una relazione di amore e odio perché noi combattevamo come militanti della sinistra l'influenza americana, ma anche quella del governo inglese, ma gli spiriti culturali delle avanguardie culturali che venivamo dall'Inghilterra erano anche le nostre, ci lavoravamo insieme. El Bundeszentrale für gesundheitliche Aufklärung di Köln era con noi vicino perché era diretto da scienziati vicini 
al SPD, che era una cosa assai rara e difficile nella UISEP perché mai aveva parlato di educazione sanitaria per $i$ problemi sanitari dei lavoratori perché li lasciava tutti a la OIT di Ginevra. (Briziarelli L, 2014, min. 48:30)]

El curso de verano del CSES inaugurado el $1958^{(68)}$ fue, durante décadas, una referencia en Europa. Sus ediciones anuales permitieron la acogida no solo de estudiantes italianos, sino también de muy numerosos extranjeros, también españoles a partir de los años setenta. Su atractivo residía en que:

El curso se basó en el método socrático (que usábamos en Londres), estoy viendo que muchos grupos están recuperando el diálogo socrático, y se organizó en diez días. Sacamos una convocatoria y vino mucha gente, alrededor de 60 personas. Se trabajaba en grupo, a la mañana se daba una clase introductoria, después dos horas de trabajo grupal para discutir lo que cada uno hacía en su propio trabajo y si se podía aplicar o no. A la tarde era sobre comunicación, se tenía que producir algo para publicar (volantes, carteles, películas). El curso se enfocaba en un tema, un problema específico (alimentación, salud mental, etc.). [Traducción del original: ...il corso era fondato sul metodo socratico (che usavamo a Londra), sto vedendo che molti gruppi stanno rilanciando il dialogo socratico, organizzato in 10 giorni. Facemmo un bando e venne molta gente, circa 60 persone. Si lavora in gruppo, la mattina si faceva una lezione di inquadramento, poi due ore di lavoro di gruppo per discutere sulle cose che ognuno faceva nel proprio lavoro e se si potevano applicare o no. E il pomeriggio era sulla comunicazione, si doveva produrre un qualche cosa per pubblicare (flanellografie, manifesti, filmine). Il corso aveva un tema, un problema specifico (alimentazione, salute mentale etc.). (Modolo MA, 2014, min. 31:00)]
Pero además, la incorporación en el mundo del higienismo y de la salud pública clásica de las ciencias sociales, especialmente la antropología médica, fue un hecho absolutamente inédito en Europa. La contribución antropológica en la formación de profesionales de la salud fue un tipo de aportación nada común en el acervo académico de la salud pública europea:

Venían personas de toda Italia a estudiar lo que era la educación sanitaria y mi padre [Alessandro Seppilli] tuvo la idea de que para estudiar educación sanitaria era necesario conocer la antropología, y así la antropología entra en el 1956 en los programas de educación sanitaria. Yo daba todos los años en verano una extensa clase magistral, un debate sobre la antropología, qué es, para qué sirve y publiqué poco después el otro trabajo sobre la OMS, el primer trabajo sobre la contribución de la antropología cultural y la educación sanitaria y desde allí comenzó una colaboración que sigue hasta hoy. [Traducción del original: Venivano da tutta Italia delle persone a studiare cosa voleva dire l'educazione sanitaria e mio padre [Alessandro Seppilli] ebbe l'idea che per studiare l'educazione sanitaria bisogna conoscere l'antropologia e così l'antropologia entra nel 1956 nei programmi di educazione sanitaria e io facevo tutti gli anni, d'estate, una lunga lezione, un dibattito sull'antropologia, cos'è, a cosa serve e pubblicai poco dopo quell'altro lavoro su l'OMS, il primo lavoro sul contributo dell'antropologia culturale e l'educazione sanitaria e da lì cominciai una collaborazione che va avanti fino ad oggi. (Seppilli T, 2014, min. 31:00, I)]

La estructura del curso correspondía al modelo participativo que habían desarroIlado los británicos y se componía de alguna clase magistral introductoria, pero, sobre todo, de talleres y actividades prácticas y participativas, articuladas en: 
...grupos temáticos. Las jornadas estaban compuestas por una clase de cualquiera de nosotros (Paolo Bartoli, Riccardo Romizzi y yo). Tullio Seppilli daba la clase inaugural de antropología médica y nosotros nos turnábamos para dar modelos culturales en salud y enfermedad, aprendizaje y difusión cultural, técnicas de recolección de datos en la comunidad, el tema de la comunicación. Luego se trabajaba en grupo, a través de talleres y, sobre todo, discusión de las distintas experiencias sobre ciertas temáticas. Yo coordinaba el grupo sobre parto y nacimiento, había muchos españoles. Nos sumergíamos todo el día en el trabajo grupal (desde las 10 hasta las 6-7 de la tarde). Trabajábamos mucho sobre los procesos de medicalización, la prevención en el campo de la salud y también el significado político. Lo concebíamos como el camino maestro de la medicalización, el desplazamiento desde la medicina de la enfermedad hacia la salud y la normalidad eran las bases del dominio de la medicina social, porque al ocuparnos de la prevención nos ocupábamos de la vida cotidiana (alimentación, sexualidad). Con el tiempo, nuestro enfoque se hizo muy crítico, invitábamos a los participantes a pensar desde lo cultural sus propios modelos, incluso los modelos científicos. [Traducción del original: ... lavori di gruppo tematici. Le giornate comprendevano una lezione frontale di qualcuno di noi (Paolo Bartoli, Riccardo Romizzi e io). Tullio Seppilli faceva la lezione inaugurale di antropologia medica e noi ci alternavamo su modelli culturali di salute e malattia, apprendimento e circolazione culturale, tecniche di rilevazione nella ricerca di comunità, il tema della comunicazione. Poi si entrava in gruppo, dove c'erano delle esercitazioni, ma soprattutto confronto tra esperienze intorno a certi temi. lo gestivo un gruppo sul parto e la nascita, erano presenti molti spagnoli. C'era un'immersione nel lavoro di gruppo tutto il giorno (dalle 10 alle 6-7 di sera). Lavoravamo molto sui processi di medicalizzazione, la prevenzione nel campo della salute anche il significato politico, ma da lì a poco noi la abbiamo considerata come la strada maestra della medicalizzazione, lo spostamento della medicina progressivo dalla malattia alla salute e alla normalità era la base del dominio della medicina nel sociale, perché occupandosi di prevenzione, ti occupavi della vita quotidiana (alimentazione, sessualità). Man mano che andava avanti nel tempo il nostro approccio era molto critico, noi invitavamo i partecipanti a considerare da un punto di vista culturale i loro stessi modelli anche quelli che loro consideravano scientifici. (Falteri $\mathrm{P}, 2014$, min. 05:54)

Aunque la antropología ocupó siempre un espacio notable, al que Tullio Seppilli jamás renunció, no estuvo exento de contradicciones entre lo que esperaban, por un lado, los antropólogos y, por otro, los salubristas:

No siempre estábamos de acuerdo con Tullio, que era mucho más médico científico que nosotros. Con los higienistas teníamos la sensación de que la perspectiva antropológica era como un ornamento, que nosotros producíamos pura charla, y que las cosas verdaderas e importantes eran los temas de la higiene. Nosotros nunca nos atrevimos a entrar en el campo de los higienistas, pero ellos sí, por un lado, nos otorgaban un espacio muy grande, por el otro, la sensación era muy clara de que también el higienista puede volverse un poco antropólogo. Sobre este punto Tullio era menos sensible, no sé si porque era hijo de un higienista o por su formación. Por eso, los que trabajaban en este ámbito se sentían un poco misioneros, hay un elemento: "llegamos nosotros, los sanamos y salvamos a todos", por un lado promueves la salud, por el otro estas medicalizando a la sociedad. [Traducción del original: In questo, spesso, non 
andavamo d'accordo con Tullio che era molto più medico scientifico di noi! Con gli igienisti avevi la sensazione che la prospettiva antropologica fosse un po'un ornamento, che tutto sommato noi facessimo delle chiacchiere perché poi le cose vere e importanti fossero i temi dell'igiene. Mentre noi non ci siamo mai azzardati ad entrare nel campo degli igienisti, loro sì, da una parte ci davano uno spazio notevole, ma dall'altra la sensazione era molto netta che anche l'igienista può fare un po' l'antropologo, su questo Tullio era meno sensibile, non so se perché figlio di un igienista o per la sua formazione. [Per questo ] coloro che lavoravano in questo ambito si sentivano un po' missionari, c'è un elemento: "arriviamo noi, vi salviamo e vi facciamo stare tutti in salute", da una parte promuovi la salute dall'altro medicalizzi la società. (Bartoli P, 2014, min. 30:00)]

Bartoli, antropólogo, pone de relieve un punto importante, consecuencia de las reservas de los antropólogos ante un proceso que, finalmente, conducía no tanto al relativismo sino, de hecho, a la profundización del proceso de medicalización. Se incardinaba, por tanto, en un debate intenso sobre la "medicalización", cada vez más presente en la agenda de la antropología médica desde finales del siglo XX ${ }^{(69)}$. Respondía al temor de que el mercado laboral de los antropólogos fuese absorbido por los sanitaristas ${ }^{(70)}$. Sin embargo, los antropólogos que trabajaban en el CSES:

...presentábamos el concepto de medicalización, pero insistiendo en que el significado era neutral, hablábamos en términos de modelos cognitivos, de comportamientos médicos en la población; no era necesariamente negativo, era tomar en cuenta lo que estaba pasando. Fueron años durante los cuales Paolo y yo hacíamos investigación de campo cerca del lago Trasimeno sobre el encuentro/ desencuentro entre la medicina popular y la oficial, a partir de las primeras especializaciones que se habían extendido en el territorio: obstetricia y pediatría. [Traducido del original: ...presentare il concetto di medicalizzazione insistendo però che il significato era neutro, ne parlavamo nei termini di modelli cognitivi, di comportamenti medici della popolazione, non era necessariamente negativo, era aver presente quello che stava accadendo. Anni in cui io e Paolo facevamo ricerca sul campo vicino al lago Trasimeno a proposito dell'incontro scontro tra medicina popolare e ufficiale a partire dalle prime specializzazioni che si erano diffuse capillarmente nel territorio: ostetricia e pediatria. (Falteri P, 2014, min. 31:47)]

Esto les permitía, aun con las limitaciones que detectaban, tener como objetivo primordial buscar un cambio de actitud de los profesionales sanitarios, ofreciendo una formación crítica en relación con las variables sociales y culturales. En Perugia:

...siempre hemos estado convencidos de que la medicina no podía ser verdaderamente social si los médicos no reciben un importante aporte cultural de parte de las disciplinas humanísticas, que no se trata solo de enseñar un poco la antropología cultural, psicología médica y sociología médica, sino de crear en la cabeza médica del estudiante un espacio para considerar al paciente no como un hombre en una camilla, sino como un hombre social. Este era nuestro pensamiento, e intentábamos que el estudiante entendiera que había una parte no estrictamente clínica en el hombre que el médico debe considerar. [...] Esto en realidad jamás ha sido logrado, jamás hemos logrado un cambio objetivo. Con la Modolo trabajamos tanto en medicina como en los cursos de capacitación del personal sanitario, introduciendo las disciplinas humanísticas y sociales, e introdujimos estos cursos más a nivel de personal no médico que médico. En 
mi curso mandábamos a los estudiantes a estudiar en un barrio, en las fábricas, en un servicio periférico de manera que entendieran, a través de este conocimiento del terreno, aquellas cosas que no conocían porque estaban solo en el hospital. Lo realizamos, pero siempre con mucha dificultad. [Traducción del original: ...noi siamo sempre stati convinti che la medicina non poteva essere veramente sociale se $i$ medici non avessero ricevuto una importante aggiunta culturale da parte delle discipline umanistiche, che non era solo insegnare un po' di antropologia culturale, psicologia medica, sociologia medica, ma di creare nella testa dello studente medico uno spazio per considerare il paziente non un uomo sul letto da visita, ma un uomo sociale, questo era il nostro ragionamento, cercavamo di far capire allo studente che c'è una parte non strettamente clinica dell'uomo che deve essere considerato dal medico. [...] Questo in realtà non è stato mai raggiunto, non si è mai avuto un cambiamento oggettivo. lo e la Modolo abbiamo lavorato sia in medicina che nei corsi di formazioni del personale sanitario introducendo discipline umanistiche sociali, quindi abbiamo introdotto questi corsi più a livello di personale non medico che medico, nel mio corso gli studenti venivamo mandati a studiare un quartiere, una fabbrica, un servizio periferico in modo che preparassero, attraverso questa conoscenza del terreno, qualcosa che loro non sanno perché loro stanno solo in ospedale. Lo abbiamo fatto però sempre con grande fatica. (Briziarelli L, 2014, min. 01:05:00)]

A pesar de este factor diferencial, del añadido crítico de las ciencias sociales, las líneas dominantes de la formación siguieron vinculadas a

...la cultura desarrollada en el centro de educación sanitaria de Londres, de Edimburgo y de Irlanda. Era la misma que nosotros llevábamos a Italia, eran elementos científicos y técnicos, que introducíamos y le incorporábamos elementos políticos; entonces estos extranjeros trabajaban con gusto con nosotros, porque Ilevábamos adelante este discurso político a través de una sociedad internacional de política sanitaria, era una asociación científica de estudiosos de salud pública y cultura sanitaria, todos de izquierda, que llevábamos a cabo un discurso de sanidad pública en el sentido socialista. [Traducción del original: ...la cultura sviluppata dal centro di educazione sanitaria di Londra, di Edimburgo e quella irlandese. Era la stessa che noi portavamo in Italia, erano elementi scientifici e tecnici, noi li introducevamo nei nostri e vi mettevamo elementi politici e quindi questi stranieri lavoravano con noi volentieri perché noi portavamo avanti questo discorso politico attraverso una società internazionale di politica sanitaria, era un'associazione sanitaria di scienziati studiosi di sanità pubblica e cultura sanitaria, tutti di sinistra, che portavano avanti un discorso di sanità pubblica nel senso socialista. (Briziarelli L, 2014, $\min$. 56:00)]

La diferencia venía de la actitud personal y del compromiso político de los salubristas y de los antropólogos que colaboraban en ello, puesto que entendían que, en la Europa del sur, "el tema de la prevención tenía para nosotros un fuertísimo valor politico" (Bartoli P, 2014, min. 1:38) que suponía:

...colaboración con el movimiento de cooperación educativa en el campo de la escuela, de los docentes, de los educadores de los servicios. El método era participativo, relacionado con el trabajo grupal, yo tenía un grupo de antropología al que venían docentes, educadores de toda Italia, y formaban grupos territoriales. [Traducción del original: ...collaborazione con il movimento di cooperazione educativa nel campo della 
scuola, degli insegnanti, degli educatori dei servizi. Il metodo era partecipativo, legato ai lavori di gruppo, io tenevo un gruppo di antropologia a cui venivano insegnanti, educatori da tutta Italia e formavano gruppi territoriali. (Falteri $\mathrm{P}$, 2014, min. 03:43)]

A diferencia del culturalismo norteamericano, del que no cabe duda que surgió el impulso inicial del relato antropológico que se exponía en Perugia, este último podía tener una perspectiva crítica relacionada, por una parte, con la antropología crítica marxista italiana y, por otra, con la significación que tenía el compromiso político en la emancipación de las clases subalternas. Por eso, las acciones de participación social incluían:

...la política, las instituciones locales, los sindicatos y los trabajadores. En los años sesenta ya teníamos una fuerte relación con el sindicato de trabajadores de metalmecánica de Terni y de Perugia con los ceramistas, los trabajadores de la Perugina, los textiles y en esta relación encontrábamos el sostén a nuestras ideas, y llevábamos el tipo de trabajo que hacíamos a los obreros de las fábricas y era útil también para afinar nuestros modelos de trabajo. Tanto es así que organizábamos para los sindicatos cursos de capacitación sobre cuidado de la salud, eran verdaderas acciones de educación sanitaria con relación a los comités de la fábrica y de los trabajadores. El CESS entró en lo social, pero recibía también de lo social elementos que nos ayudaban a seguir adelante con nuestro discurso, que era difícil porque no venía aceptado por la medicina oficial, ni por la higiene oficial. Era fácil para nosotros cuando entregábamos los resultados de nuestras investigaciones, hablar con los trabajadores y explicarles lo que sucedía. Con los ceramistas de Deruta trabajamos mucho para entender el grado de daño producido por el plomo y para llevar adelante sus reivindicaciones. Era una mezcla de trabajo, trabajo técnico de higienista y político de educar y contribuir a que los trabajadores adquieran conocimientos para llevar a cabo su lucha contra el patrón. [Traducción del original: ...la politica, le istituzioni locali, i sindacati e i lavoratori. Già negli anni 60 noi avevamo forti legami con il sindacato dei lavoratori metalmeccanici a Terni e a Perugia con $i$ ceramisti, $i$ lavoratori della Perugina, il tessile e in questo rapporto trovavamo sostegno alle nostre idee e portavamo il tipo di lavoro che facevamo con gli operai nelle fabbriche e ci serviva anche come affinamento dei nostri modelli di lavoro. Tanto è vero che organizzammo per $i$ sindacati corsi di formazione sulla tutela della salute che erano vere e proprie azioni di educazione sanitaria nei confronti dei consigli di fabbrica e dei lavoratori. Il CESS entrò nel sociale, però recepiva anche dal sociale elementi e che ci aiutavano a tirar avanti il nostro tipo di discorso che era difficile perché non veniva accettato dalla medicina ufficiale né dalla igiene ufficiale. Era facile per noi quando consegnavamo i risultati delle nostre indagini, parlare con i lavoratori e spiegare cosa succedeva. Con $i$ ceramisti di Deruta lavorammo molto per capire il grado di danno prodotto dal piombo e per portare avanti le loro rivendicazioni. Era un mescolamento di lavoro, tra lavoro tecnico d'igienista e politico di istruire e far sì che $i$ lavoratori acquisissero conoscenze per supportare la loro lotta contro il padrone. (Briziarelli L, 2014, min 19:23)]

La aparente radicalidad política del proyecto fue, en sí mismo, un obstáculo. A pesar de los debates acerca de la participación en salud, el compromiso local planteaba problemas para su generalización y eso hizo que sus

...ideas se difundieran poco. Venían aquí de todas partes de Italia, pero el modelo no se propagaba. No se creaban otros 
puntos en los que se hiciera lo mismo. La resistencia más grande fue la de los higienistas, porque no solo no aceptaban la propuesta, sino las rechazaban, le hicieron la guerra tanto a [Alessandro] Seppilli como a sus estudiantes higienistas, no aceptaron que la educación sanitaria fuese un instrumento científicamente validado. La ciencia, para ellos, era aquella de los números, las tablas, la significación, lo contrario al discurso cualitativo, hoy en día todos estamos de acuerdo que es indispensable, era ridículo. La situación era difícil, era una lucha, pero éramos luchadores. [Traducción del original: ...idee si irradiarono poco. Venivano qui da tutte le parti d'Italia, però il modello non si propagava. Non si creavano altri punti in cui si faceva la stessa cosa. La resistenza più grossa fu quella degli igienisti perché non solo non accettarono le proposte, ma le rifiutarono, fecero guerra sia a [Alessandro] Seppilli che ai suoi allievi igienisti, non accettarono che l'educazione sanitaria fosse uno strumento scientificamente validato. La scienza per loro era quella dei numeri, delle tabelle, la significatività, invece il discorso di tipo qualitativo, oggi ormai siamo tutti d'accordo che sia indispensabile, era ridicolo. La situazione fu difficile, era una lotta, ma eravamo combattenti. (Briziarelli L, 2014, min 18:00)]

Un segundo obstáculo debe atribuirse a la radicalización cuantitativista de las profesiones sanitarias y del salubrismo. El modelo perusino se basaba en una mirada etnográfica, cualitativa y local, lo cual suponía, para los salubristas un reciclaje profesional y asumir una actitud ante los sujetos de intervención mucho más relativista y respetuosa. El entrenamiento en técnicas etnográficas es mucho más complejo y tiene unos costes personales y de aprendizaje. A pesar de la presencia de las ciencias sociales en los cursos de verano, la brevedad de las intervenciones permitía que aceptaran ...la dimensión cualitativa de la investigación [...] pero no la entendían mucho, no entendían la importancia del método cualitativo. Era mejor un cuestionario aplicado a 100 personas que una entrevista semiestructurada de tipo cualitativa realizada a un curandero. Esto nunca lo han dicho de forma explícita, pero la sensación era esta, que la ciencia no se hace con el dato cualitativo. Por supuesto que nosotros no negábamos la importancia del dato cuantitativo, del dato estadístico, decíamos que no dice todo. Yo no veo ningún conflicto, pero para muchos higienistas esto no era fácil de entender. [Traducción del original: ...gli aspetti qualitativi della ricerca li accettavano ma non li capivano molto, non veniva colta l'importanza del metodo qualitativo. Era meglio un questionario somministrato a 100 persone che non una intervista semi-strutturata di tipo qualitativo fatta a un guaritore. Questo non ci è stato mai detto esplicitamente, però la sensazione era questa che la scienza non si fa con il dato qualitativo, naturalmente noi non negavamo l'importanza del dato quantitativo, del dato statistico, diciamo che non dice tutto, io non vedo nessun conflitto, però per molti igienisti questa cosa non era facile di capire. (Bartoli P, 2014, min. 42:47)]

Para los antropólogos académicos adaptarse a las necesidades de la educación sanitaria resultaba complicado. En ese sentido el CSES, perdió influencia ya durante los años noventa:

Estábamos de acuerdo porque, como es sabido, teníamos concepciones de educación sanitaria muy abiertas, sin embargo, era una dialéctica interna muy fuerte, que al final se agotó, más allá no podíamos seguir, y poco a poco se terminó también la experiencia del centro experimental. Yo he estado muchos años en la dirección del centro aunque no participaba mucho del curso, 
las relaciones se mantuvieron, pero el curso se iba apagando poco a poco. [Traducción del original: Andavamo d'accordo perché avevano concezioni, come è noto, di educazione sanitaria molto aperta, ma nel merito c'era una dialettica molto forte interna, alla fine si è esaurita, più in là di tanto non potevamo andare avanti e poi man mano si è spenta anche l'esperienza del centro sperimentale. lo sono stata molti anni nel direttivo del centro pur non partecipando più al corso, $i$ rapporti sono rimasti, però il corso si stava a mano a mano spengendo. (Falteri P, 2014, min. 48:00)]

No cabe duda de que la crisis del modelo del CSES se corresponde con los cambios ideológicos que hubo entre las conferencias de Ottawa y Yakarta. Los presupuestos de esta última condujeron a un tipo de acción pragmática, con menor dosis de compromiso social, personal y político. Por ello, podemos concluir esta parte con el diálogo entre Paóla Falteri y Paolo Bartoli en la primavera de 2014 en Perugia:

Bartoli: -Me gustaría saber por qué de repente el interés por la antropología ha desaparecido [lo vorrei capire perché all'improvviso l'interesse per l'antropologia è svanito. (Bartoli P, 2014, min. 41:10)].

Falteri: -Paolo, no seas tonto, porque nuestro enfoque era crítico, aunque en sentido constructivo [Paolo sei un po'tonto, perché il nostro approccio era critico anche se in senso costruttivo. (Falteri P, 2014, min.41:25)]

\section{LA EDUCACIÓN SANITARIA EN LA ESPAÑA FRANQUISTA: DE LAS DIVULGADORAS RURALES A ADOLFO MAILLO}

El nuevo Estado franquista mantuvo algunas propuestas sanitarias y educativas de la
II República por la necesidad de combatir el hambre, la mortalidad infantil y las enfermedades infecciosas. Sin embargo, la educación sanitaria no fue jamás prioritaria porque los responsables de la Dirección General de Sanidad (DGS) eran escépticos sobre su efectividad $^{(71)}$. Editaron carteles y fomentaron emisiones radiofónicas ${ }^{(72,73,74)}$ y, sobre todo, editaron dos colecciones de libros. La primera colección denominada "Al Servicio de España y del Niño Español" (ASENE) publicó 311 libros entre 1938 y $1964^{(75)}$ y refleja una retórica nacionalista y pronatalista. Su objetivo era reducir la mortalidad, adiestrar a los profesionales y la propaganda. Algunos volúmenes hablan de educación sanitaria ${ }^{(76)}$. La segunda colección era "Folleto para médicos" que publicó 76 títulos pensados para médicos, entre 1944 y 1964, bajo el sello de la Dirección General de Sanidad. Aunque algunos estuvieron dirigidos a la población en general, se ignora su difusión real y, por lo tanto, cualquier posibilidad de valorar cierto impacto en la conducta sanitaria de la población ${ }^{(77)}$.

El intento más interesante en el periodo 1941-1959 fue el programa de divulgadoras rurales de la Sección Femenina de la agrupación política Falange Española de las Juntas de Ofensiva Nacional Sindicalista, en la línea de los médicos descalzos. Encuadraba mujeres jóvenes para trabajar en el ámbito rural en programas de puericultura, buenos hábitos alimentarios y recomendaciones de higiene. La mayoría se reclutaban en sus mismas localidades puesto que las que procedían de las ciudades tenían problemas de inserción ${ }^{(77)}$. Frente a la modestia de esos programas están las actuaciones destinadas a extender la cobertura del Seguro Obligatorio de Enfermedad, que se limitaba a proveer servicios médicos y asistenciales a los asegurados ${ }^{(33)}$.

España no ingresó a la Union internationale pour l'étude scientifique de la population (UIESP) hasta 1959. Cuando se incorporó, la Dirección General de Sanidad comenzó a publicar unos Folletos específicos sobre organismos internacionales ${ }^{(78)}$, así como también la obra de Claire E. Turner 
sobre educación sanitaria en la escuelas ${ }^{(79)}$. El principal aporte español a las actividades de la UIESP fue la organización de su VI Congreso en Madrid, en 1965, celebrado en una institución tan emblemática de la España franquista como la sede central de la Organización Sindical Española. Se concibió como una operación de imagen para dar visibilidad al régimen. La participación internacional fue importante:

Seppilli no tenía relación con los españoles, pero tenía relaciones con el mundo científico portugués y brasileño, porque toda su vida escribió reseñas y artículos para una revista brasileña que se encontraba también en Portugal. En España, en la conferencia de 1966 se había relacionado con el que llegó a ser presidente de la Unión Internacional de Educación Sanitaria, Bosch Marin, que era un pediatra. Una persona abierta, no era un franquista aunque fue presentado como un hombre del aparato franquista. La conferencia se realizó en la Casa de Falange, en los sindicatos. Fuimos $y$ encontramos un mundo muy vivaz: argentinos, brasileños que trajeron a la conferencias vientos nuevos que el régimen no impidió. [Traducción del original: Seppilli non aveva relazioni con gli spagnoli, però le aveva con il mondo scientifico portoghese e brasiliano perché per tutta la sua vita fece recensioni e articoli per una rivista brasiliana che c'era anche in Portogallo. In Spagna alla conferenza del '66 aveva legato con quello che diventò il presidente dell'Unione internazionale di Educazione alla Salute, Bosch Marin, che era un pediatra. Una persona aperta, non era franchista, anche se fu presentato come un uomo dell'apparato franquista. La conferenza si tenne nella Casa della Falange, nei sindacati. Noi andammo lì e trovammo un mondo molto vivace: argentini, brasiliani che portarono nella conferenza venti nuovi che il regime non impedi. (Briziarelli L, 2014, min. 45:00)]
El congreso tuvo escasa repercusión en las políticas sanitarias españolas. En concordancia con el evento, se publicó un libro colectivo sobre educación sanitaria ${ }^{(80)}$, en el que participó el pedagogo Adolfo Maíllo $(1901-1995)^{(81)}$, artífice de los intentos de importación del nuevo modelo de "educación sanitaria escolar" durante la década de $1960^{(82)}$. Maíllo era el director del Centro de Orientación y Documentación Didáctica de Enseñanza Primaria (CEDODEP), organismo técnico encargado de pilotar la reforma de la enseñanza primaria franquista. En este contexto reformista, se interesó por la educación sanitaria de los escolares ${ }^{(83)}$. Creía en un abordaje interdisciplinario de la educación sanitaria y que esas enseñanzas no podían limitarse a la escuela y a los contenidos curriculares, influido como estaba por el curso de verano de Perugia ${ }^{(68)}$ y por su lectura de obras de la antropología y sociología norteamericana ${ }^{(84)}$. Estudios recientes ${ }^{(85)}$ consideran su actitud como el producto de una amplia experiencia de campo en comunidades rurales, donde trabajó primero como maestro y, posteriormente, en el ámbito de las campañas de alfabetización. Consideraba que el campesinado podía ser analfabeto, pero no incivilizado y que, antes de alfabetizar, era necesario un trabajo previo que incorporase las dimensiones locales en términos geográficos, económicos, sociológicos o culturales. A partir del conocimiento de lo local era posible poner en juego una "educación basada en la comunidad". Maíllo fue el ideólogo de la acción educativa asociada a la implantación de salas públicas para ver televisión en comunidades rurales (teleclubs) ${ }^{(86)}$. Sus ideas no tuvieron trascendencia por las contradicciones que ese modelo suponía durante el franquismo y por la entrada en España de una nueva generación de tecnócratas académicos.

\section{Perugia en la España de la transición}

La modestia de la educación sanitaria del franquismo, con excepción de las orientaciones nutricionistas en los años sesenta ${ }^{(87,88)}$ pone de relieve la distancia entre España y los 
desarrollos llevados a cabos en otros países europeos. El régimen apostó por la Seguridad Social, un dispositivo asistencial no exento de críticas ${ }^{(89)}$ sobre el cual construía su legitimidad. El "seguro" asistencial, desde los años sesenta, propició un debate que culminaría con la reforma sanitaria de la transición democrática ${ }^{(90)}$. El nuevo esquema organizativo de la sanidad no rompió completamente con el asistencialismo del modelo falangista ${ }^{(91)}$, a pesar de las advertencias críticas sobre el papel que la atención primaria y la educación para la salud debían tener en ella, y que pretendían ajustar la reforma española a las directrices de Alma-Ata.

En el debate de los años setenta, la educación sanitaria tuvo un lugar muy marginal, que empezó a cambiar con la puesta en marcha del Ministerio de Sanidad en 1977. A principios de los años ochenta se observa una renovación de ideas sobre la educación sanitaria. Durante esa década un tercio de los participantes al curso de verano del CSES eran españoles:

...la participación de los españoles era estimulante, la mayoría eran mujeres, tenían una energía, un deseo de hacer y de cambiar mucho más fuerte que en Italia en esos años de transición, a menudo eran incluso más competentes. [Traducción del original: ...era entusiasmante la partecipazione degli spagnoli, in gran parte donne, avevano un'energia, un desiderio di fare e di cambiare molto superiore agli italiani, in quegli anni di transizione, spesso erano anche più preparati. (Falteri P, 2014, min. 15:00)]

...aportaron un elemento de acción, a menudo los estudiantes son un poco pasivos, tú hablas y ellos escuchan; al contrario con ellos había mucha más efervescencia. [Traducción del original: ...hanno aportato un elemento di attività, spesso gli allievi sono un po' passivi, tu parli e loro ascoltano, mentre con loro c'era molta più effervescenza. (Bartoli P, 2014, min. 16:30)]
Algunos hicieron estancias más largas. Más adelante, organismos locales, en Madrid, Zaragoza y otras ciudades organizaron cursos locales. Los contenidos de antropología en esas formaciones eran una novedad para los salubristas españoles. Para muchos de ellos fue significativo el papel que jugó la publicación de 65 artículos, entre 1985 y 1995, sobre temas de antropología, relacionados con la medicina o problemáticas afines en la revista Jano: Medicina y Humanidades, distribuida gratuitamente a los médicos de todo el país.

La conexión entre esos sectores y la antropología profesional en España tardó en producirse por la lentitud de la institucionalización de esta última ${ }^{(92)}$. Entre 1988 y 1989, a instancias de Lluis Salleras y de la mano de Ignasi de Juan Creix, el Institut Català de la Salut de Barcelona organizó un curso en el que participaron salubristas y antropólogos médicos como Paolo Bartoli ${ }^{(93)}$, Eduardo Menéndez, Oriol Romaní y Josep M. Comelles. Tuvo continuidad en distintas ciudades del Estado y la antropología médica italiana apadrinó el proyecto formativo de posgrado de la Universitat Rovira i Virgili en Tarragona, en 1994.

El CSES tuvo un indudable magisterio en una generación entera de los especialistas en salud pública y de la enfermería comunitaria de perfil más progresista. En la década de 1990, salubristas progresistas españoles afirmaban, en privado, que el modelo del CSES formaba parte del pasado. No obstante, dos décadas más tarde siguen activos parte de ellos en instituciones como el Sistema de Asesoramiento y Recursos en Educación para la Salud (SARES) del Gobierno de Aragón ${ }^{(94)} \mathrm{O}$ algunos servicios de salud comunitaria municipales mantienen activa esa llama.

\section{CONCLUSIONES}

En los años ochenta, noventa viajábamos por toda Italia en las USL [Unità Sanitaria Locale], que ahora se Ilaman ASL o AUSL [Azienda Unità Sanitaria Locale], pero 
después no nos Ilamaron más de ningún lado, en el país había un interés muy fuerte por la prevención y la educación sanitaria; me parece que este interés se ha desvanecido. [Traducción del original: Noi negli anni 80-90 giravamo in tutta Italia nelle USL ora si chiamano ASL o AUSL, ma poi non ci hanno chiamato più da nessuna parte, c'era nel paese un'attenzione molto forte ai temi della prevenzione e dell'educazione sanitaria, mi sembra che quest'attenzione sia venuta meno. (Falteri P, 2014, min 01:01:20)]

Las cuatro décadas de perspectiva de Paola Falteri ponen de relieve un cambio sustancial intensificado tras la Conferencia de Yakarta y que señala la progresiva subalternidad de los proyectos participativos de base local que tuvieron tanta relevancia desde los años cincuenta. No es menos cierto que, en los proyectos iniciales, la presencia de los médicos era importantísima, mientras que en las últimas décadas la figura de la enfermería comunitaria ha adquirido un peso evidente. En el proyecto inicial del CSES, la antropología médica se impartía para llenar un hueco formativo en ciencias sociales. Era indispensable para compensar el creciente biologicismo de la clínica pero, sobre todo, para ofrecer herramientas de investigación, de base etnográfica, imprescindibles para poder comprender la diversidad cultural local. En los años en los que se puso en marcha el centro perusino, la antropología médica stricto sensu no existía como tal ${ }^{(95)}$. Se importó, críticamente, la antropología aplicada estadounidense y la pedagogía progresista para fundamentar la educación sanitaria, algo muy novedoso en Europa.

Este panorama ha cambiado profundamente, en especial por el papel que ha asumido la enfermería comunitaria en la educación para la salud y la promoción de la salud, precisamente como uno de los efectos de Alma-Ata y de los objetivos expresados por las conferencias de Ottawa y Yakarta. En la nueva enfermería comunitaria y en los manuales de salud pública, la presencia de las ciencias sociales, tanto de la sociología como de la antropología médica ocupan un lugar relevante en la definición conceptual y en las síntesis de carácter teórico. Desde el punto de vista instrumental, sucedáneos de la etnografía como la teoría fundamentada han ocupado, en parte, su lugar. Se trata de contenidos y técnicas que tienen presencia en los currículos académicos de la enfermería en general, puesto que tres de las más importantes reformadoras, Henderson, Lenninger y Collière ${ }^{(96,97,98)}$ se doctoraron en antropología. No es extraño, hoy día, encontrar en manuales y libros de texto españoles sobre medicina y enfermería comunitaria la definición de educación sanitaria que hiciera Alessandro Seppilli que encabeza este artículo ${ }^{(99)}$.

Con perspectiva histórica, el CSES fue como un punto de referencia y de vanguardia en una etapa brillante de la historia sanitaria en general y de la educación sanitaria en particular. Entre la Conferencia de San Francisco y la de Yakarta 1997, podemos considerar que la hegemonía del pensamiento socialdemócrata y social cristiano, con amplias demandas de radicalización democrática, se tradujo en la incentivación de la acción colectiva civil a escala local frente al simple empowerment individual ${ }^{(62)}$. El correlato en la concepción de la educación en salud fue evidente.

Desde la perspectiva de las ciencias sociales aplicadas en Europa, el CSES fue un experimento de vanguardia, innovador por la incorporación explícita y crítica de la antropología a su agenda. No puede reducirse a la relación accidental de la relación paternofilial entre Alessandro y Tullio Seppilli. Alessandro Seppilli, cuya esposa era Anita Schwarzkopf, también antropóloga, se acercó a la antropología por lo que esta ciencia social podía aportar a la comprensión y al diagnóstico de los problemas de salud locales. Tullio Seppilli supo construir un relato orgánico, cuyas raíces están en su maestro Ernesto de Martino, que superó los límites del relativismo de la antropología cultural estadounidense. A su vez, sus discípulos, involucrados en el proyecto del CSES, no tuvieron inconveniente, por su compromiso político y social, en responder 
a las demandas de la antropología aplicada que les hacían los profesionales de la salud.

Posiblemente, en Europa, solo Italia presentaba las condiciones para llevar a cabo esta iniciativa innovadora. El rígido academicismo de la medicina y la antropología europeas de su tiempo solo podían romperse a partir de la renovación del compromiso social de los profesionales, tanto de médicos y otros profesionales sanitarios, como de los propios antropólogos académicos. Es la imposibilidad del compromiso y la participación lo que explica su fracaso en la España del tardofranquismo y su éxito tardío durante la transición democrática española.

\section{AGRADECIMIENTOS}

Esta investigación ha sido financiada por el Ministerio de Economía y Competitividad español, a través de los proyectos "De la propaganda sanitaria a la educación para la salud: ideología, discursos y saberes en la España de Franco (1939-1975)" HAR2012-34588 y “Reforma sanitaria y promoción de la salud en el tardofranquismo y la transición democrática: nuevas culturas de la salud, la enfermedad y la atención" HAR2015-64150-C2-1-P (MINECO/FEDER, UE). Nuestro agradecimiento a Tullio Seppilli, Paolo Bartoli, Paola Falteri, Maria A. Modolo, Anna Ferrari, Maurizo Mori (fallecido en 2016) y Lamberto Briziarelli, que trabajaron o trabajan en el Centro Sperimentale per l'Educazione Sanitaria de Perugia (Italia), o colaboran con él.

\section{REFERENCIAS BIBLIOGRÁFICAS}

1. Seppilli A. Educazione sanitaria: Lezioni e conference. Perugia: Università degli Studi di Perugia; 1964.

2. Organización Mundial de la Salud. Declaración de Yakarta sobre la promoción de la salud en el siglo XXI [Internet]. 1997 [citado 8 sep 2016]. Disponible en: http://tinyurl.com/lkxczj5.

3. Rosen G. De la policía médica a la medicina social: ensayos sobre la historia de la atención a la salud. México: Siglo XXI Editores; 1985.

4. Cosmacini G. Storia della medicina e della sanità in Italia: dalla peste nera ai giorni nostri. Roma: Laterza; 2015.

5. Rodríguez Ocaña E. La constitución de la medicina social como disciplina en España (1882-1923). Madrid: Ministerio de Sanidad y Consumo; 1987.
6. Castejón-Bolea R, Perdiguero-Gil E, PiquerasFernández JL. La imágenes de la salud: cartelismo sanitario en España (1910-1950). Alicante: Instituto Alicantino de Cultura "Juan Gil Albert", Consejo Superior de Investigaciones Científicas; 2012.

7. Diasio N. La science impure: anthropologie et médecine en France, Grande-Bretagne, Italie, Pays-Bas. Paris: Presses Universitaires de France; 1999.

8. Bartoli P. Farmaci e sacramenti: Organizzazione sanitaria e parroci di campagna nella seconda mettè del'Ottocento. Sanità, Scineza e Storia. 1985;2:121-140.

9. Comelles JM. Da superstizione a medicina popolare: La transizionae da un concetto religioso a un concetto medico. AM: Rivista della Società Italiana di Antropologia Medica. 1996;(1-2):57-87.

10. Comelles JM. From superstition to folk medicine: The transition from a religious to a medical concept. Medical Anthropology Theory. 2016;3(2):269-305.

11. Bartoli P, Falteri P. La medicina popolare in Umbria dalla fine dell' 800 ad oggi: permanenze e transformazioni. En: Pastore A, Sorcinelli P, (eds.). Sanità e Società Emilia-Romagna, Toscana, Marche, Umbria, Lazio Secoli XVI-XX. Udine: Casamassima; 1987. p. 167-208.

12. Bronzini GB. Antropologia e medicina popolare: Note sugli studi dei positivisti italiani. La Ricerca Folklorica. 1983;(8):13-17.

13. Cirese AM. Cultura egemonica e culture subalterne: Rassegna degli studi sul mondo popolare tradizionale. 2a ed. Palumbo: Palermo; 1973.

14. Cocchiara G. Storia del folklore in Italia. Palermo: Sellerio; 1981. 
15. Angioni G. Une démo-ethno-anthropologie? Des pères fondateurs aux problèmes actuels. Ethnologie Française. 1994;24(3):475-483.

16. Cuturi F. Nuevas tendencias en los principales países de Europa Occidental: Italia. Anales de la Fundación Joaquín Costa. 1989;(6):84-91.

17. Comelles JM, Prat J. El Estado de las Antropologías: Antropologías, folclores y nacionalismos en el Estado Español. Antropologia. 1992;(3):35-61.

18. Gramsci A. Los intelectuales y la organización de la cultura. México: Nueva Visión; 1975.

19. Gramsci A. Cuadernos de la Carcel 4: Literatura y Vida Nacional. México: Juan Pablos Editor; 1986.

20. Gallego FG. El evangelio fascista: la formación de la cultura política del franquismo (1930-1950). Madrid: Crítica; 2014.

21. Giorgi C. Le politiche sociali del fascismo. Studi Storici: Rivista Trimestrale dell'Istituto Gramsci. 2014;55(1):93-108.

22. Giorgi C. L'Istituto nazionale fascista di previdenza sociale: temi e problemi. Le Carte e la Storia. 2003;IX(2):165-174.

23. Taroni F. Politiche sanitarie in Italia. Roma: II Pensiero Cientifico; 2011.

24. Vinci S. Il fascismo e la previdenza sociale. Annali della Facoltà di Giurisprudenza di Taranto. 2011;IV:709-729.

25. Thomàs i Andreu JM. La Falange de Franco: fascismo y fascistización en el régimen franquista, 1937-1945. Barcelona: Plaza \& Janés; 2001.

26. Gil Pecharromán J. El Movimiento Nacional: 1937-1977. Barcelona: Planeta; 2013.

27. Marias Cadenas S. Por España y por el campo: la Sección Femenina en el medio rural oscense (1939-1977). Huesca: Instituto de Estudios Altoaragoneses; 2011.

28. Pons Pons J, Vilar Rodríguez M. Labour repression and social justice in Franco's Spain: the political objectives of compulsory sickness insurance, 1942-1957. Labor History. 2012;53(2):245-267.

29. Cenarro Lagunas Á. La Sonrisa de Falange: Auxilio Social en la guerra civil y en la posguerra. Barcelona: Crítica; 2006.

30. Richmond K. Las mujeres en el fascimo español: la sección femenina de la falange 1934-1959. Madrid: Alianza Editorial; 2004.
31. Instituto Nacional de Previsión. Alocución del Sr. Ministro de Trabajo sobre el Seguro de Enfermedad. Madrid: Instituto Nacional de Previsión; 1953.

32. Aznar S. Las fronteras de los Seguros Sociales. Madrid: Publicaciones del Instituto Nacional de Previsión; 1942.

33. Vilar-Rodriguez M, Pons-Pons J. The introduction of sickness insurance in Spain in the first decades of the Franco dictatorship (1939-1962). Social History of Medicine. 2012;26(2):267-287.

34. Rodriguez-Ocaña E. La asistencia médica colectiva en España hasta 1936. En: Historia de la acción social pública en España: beneficencia y previsión. Madrid: Centro de Publicaciones, Ministerio de Trabajo y Seguridad Social; 1990. p. 321-361.

35. Fonio C, Agnoletto S. Surveillance, repression and the welfare state: Aspects of continuity and discontinuity in post-fascist Italy. Surveillance \& Society. 2013;11(1/2):74-86.

36. Atenza Fernández J, Martínez Pérez J, (eds.). El Centro Secundario de Higiene Rural de Talavera de la Reina y la sanidad española de su tiempo [Internet]. Toledo: Junta de Comunidades de Castilla-La Mancha; 2001 [citad 26 oct 2016]. Disponible en: http://tinyurl.com/kygk8ka.

37. Terron Bañuelos A, Comelles JM, Perdiguero-Gil E. Schools and Health Education in Spain during the Dictatorship of General Franco (1939-1975). History of Education Review. 2017 (en prensa)

38. Casero E. La España que bailó con Franco: Coros y danzas de la Sección Femenina. Madrid: Nuevas Estructuras; 2000.

39. Morán G. El maestro en el erial: Ortega y Gasset y la cultura del franquismo. Barcelona: Tusquets; 1998.

40. Perdiguero-Gil E, Comelles JM. Folklore médico y educación sanitaria en las dos primeras décadas del Franquismo. En: Campos Marínn R, Gonzaléz de Pablo A, Porras Gallo I, Montiel L, (eds.). Medicina y poder político. Madrid: Sociedad Española de Historia de la Medicina; 2014. p. 289-293.

41. Castillo de Lucas A. Folkmedicina: medicina popular, folklore médico, etnomedicina, demoiatria etnoiátrica. Barcelona: Dossat; 1958.

42. Perdiguero E, Comelles JM. Medicina popular, compromiso profesional y educación sanitaria en España. Scripta Ethnologica. 2014;(XXXVI):7-40. 
43. Campos J, Miguel J. Sociólogos-de-batablanca y médicos-con-barba: Relaciones entre las ciencias sociales y la medicina en España. Revista Española de Investigaciones Sociológicas. 1981;15(81):133-141.

44. Gramsci A. La questione meridionale. Torino: Eunadi; 1945.

45. World Health Organization. Expert Committee on School Health Services: Report on the First Session [Internet] Geneva: World Health Organization; 1951 (Technical Report Series No 30) [citado 26 oct 2016]. Disponible en: http://tinyurl. $\mathrm{com} / \mathrm{knsdkz5}$.

46. Comelles JM, Riccò I, Perdiguero-Gil E. Tullio Seppilli, I'éducation pour la santé et la fondation de I'anthropologie médicale italienne. Curare. 2014;37(2):85-99.

47. Redondo Rincón MG. El Seguro Obligatorio de Enfermedad en España: responsables técnicos y políticos de su implantación durante el franquismo. [Tesis de doctorado]. Madrid: Universidad Complutense de Madrid; 2013.

48. Gil Pecharromán J. Con permiso de la autoridad: la España de Franco (1939-1975). Madrid: Temas de Hoy; 2008.

49. Comelles JM. Preocupaciones, enfermedades folk y educación en la Cataluña franquista (19391959). En: Perdiguero-Gil E, Comelles JM, (eds.). Medicina y Etnografía en Cataluña. Madrid: Consejo Superior de Investigaciones Científicas; 2015. p. 171-202.

50. Comelles JM, Brigidi S. Fictional encounters and real engagements: the representation of medical practice and institutions in Medical TV shows. Actes d'Història la Ciència i la Tècnica. 2014;7:17-34.

51. Modolo MA, Mamon J. Long way to Health Promotion Trough IUHPE Conferences 1951-2001. Perugia: Interuniversity Experimental Centre for Health Education; 2001.

52. Dorolle P. Ethnologie et problèmes sanitaires. Revue Internationale de la Croix-Rouge et BuIletin international des Societes de la Croix-Rouge. 1953;35(412):301-16.

53. World Health Organization. Teacher preparation for health education. Report of a Joint WHO/UNESCO Expert Committee [Internet]. Geneva: World Health Organization; 1960 (Technical Reports Series No 193) [citado 26 oct 2016]. Disponible en: http://tinyurl.com/kbh4e2r.
54. Aguirre Beltrán G. La medicina indígena. América Indígena. 1947;7(2):109-125.

55. Aguirre Beltrán G. Antropología médica: sus desarrollos teóricos en México. Veracruz: Universidad Veracruzana; 1994.

56. Caudill W. Applied anthropology in medicine. En: Kroeber A, (ed.). Anthropology Today. Chicago: Chicago University Press; 1953. p. 771-806.

57. Paul BD. Health, culture and community: case studies of public reactions to health programs. New York: Russell Sage Foundation; 1955.

58. Seppilli T. Contributo alla formulazione dei rapporti tra prassi igienico-sanitaria ed etnologia. En: Atti della XLV Riunione della Società Italiana per il Progresso delle Scienze. Roma: Tipografia Editrice Italia; 1955. p. 3-20.

59. Comelles JM. Writing at the margin of the margin: medical anthropology in Southern Europe. Anthropology \& Medicine. 2002;9(1):7-23.

60. Organización Mundial de la Salud. Conferencia Internacional sobre Atención Primaria de Salud, Alma-Ata, URSS, 6-12 de septiembre de 1978 [Internet]. Washington DC: Organización Panamericana de la Salud [cited 8 sep 2016]. Disponible en: http://tinyurl.com/kg8s8gv.

61. Organización Mundial de la Salud. Carta de Ottawa para la Promoción de la Salud [Internet]. Washington, DC: Organización Panamericana de la Salud; 1986 [cited 2016 sep 8]. Disponible en: http://tinyurl.com/lp6lfcr.

62. Comelles JM. La dévolution au domaine du local des politiques étatiques de santé et de protection sociale. En: Assier-Andrieu L, Sala R, (eds.). La ville et les pouvoirs. Perpignan: Presses Université de Perpignan; 2000. p. 539-556.

63. Levi C. Cristo si è fermato a Eboli. Firenze: Eunadi; 1945.

64. Pazzini A. La medicina popolare in Italia. Trieste: Zigiotti; 1948.

65. De Martino E. II mondo magico: prolegomen a una storia del magismo. Torino: Einaudi; 1948.

66. Bernardi G. Magia psicoterapeutica: Sul tema del "rito e cambiamento psicoterapeutico" in E de Martino e G Bateson. La Ricerca Folklorica. 1988;(17):37-41.

67. De Martino E. La terra del rimorso. Milano: II Saggiatore; 1961. 
68. Atti dell'1, corso estivo di educazione sanitaria: Perugia, 4-21 settembre 1958. Perugia: Centro Sperimentale di Educazione Sanitaria; 1959.

69. Morgan LM. The medicalization of anthropology: a critical perspective on the criticalclinical debate. Social Science \& Medicine. 1990;30(9):945-950.

70. Comelles JM. El renacimiento de lo cultural en el Estado del Bienestar. AM: Rivista della Società Italiana di Antropologia Mèdica. 2004;(1718):87-108.

71. Perdiguero-Gil E. Propaganda y "educación sanitaria" en el ideario médico-social del Franquismo a través de la revista SER. En: PerdigueroGil E, (ed.). Política, salud y enfermedad en España: de la transición democrática al desarroIlismo. Alicante: Editorial Electrónica de la Universidad Miguel Hernández de Elche; 2015.

72. Jiménez Lucena I, Ruiz Somavilla MJ, CasteIlanos Guerrero J. Un discurso sanitario para un proyecto político: La educación sanitaria en los medios de comunicación de masas durante el primer franquismo. Asclepio. 2002;LIV(1):201-218.

73. Bravo J. Algunas consideraciones sobre propaganda en general y propaganda sanitaria en particular. Madrid: DGS; 1951.

74. Cayuela Sánchez S. Psiquiatría y educación socio-sanitaria en la España franquista. En: Campos Marín R, Gonzaléz de Pablo A, Porras Gallo I, Montiel L, (eds.). Medicina y poder político. Madrid: Sociedad Española de Historia de la Medicina; 2014. p. 307-311.

75. Salazar Agulló M, Martínez Marco, EBernabeu-Mestre J. La salud materno-infantil durante el franquismo: notas bibliométricas sobre el programa "Al servicio de España y del niño español". Asclepio. 2007;59(1):285-314.

76. Bosch Marín J, Blanco Otero M, Cañellas F, Bravo E. Salud y educación sanitaria. En: Al Servicio de España y del Niño Español No 298. Madrid: Direccion General de Sanidad; 1962.

77. Perdiguero-Gil E, Comelles JM. The weakness of health education in the Francoist system. European Social Science History Conference Session: Intersections between Health and Education throughout the XXth Century. Valencia, 29 de marzo-2 de abril de 2016.

78. Bermúdez Pareja M. Sanidad internacional. Organización Mundial de la salud (Folleto para sanitarios). Madrid: Dirección General de Sanidad; 1956.
79. Turner CE. Preparación del maestro en educación para la salud. En: Al Servicio de España y del Niño Español No 264. Madrid: Dirección General de Sanidad; 1961.

80. De la Quintana P, Aracama Gorosabel JJ, Maillo A et al. Problemas de educación sanitaria: Curso desarrollado como contribución a la VI Conferencia de la Unión Internacional de Educación Sanitaria. Madrid: Publicaciones de la Sociedad Española de Higiene y Medicina Social; 1965.

81. Maillo A. Curriculum Vitae: Hitos y huellas del camino (1901-1984). Madrid: Gráficas Impresas; 1988.

82. Terrón Bañuelos A. La educación sanitaria escolar, una propuesta curricular importada para la escuela española del Desarrollismo. Education Policy Analysis Archives/Archivos Analíticos de Políticas Educativa. 2015;23(19):1-31.

83. Maíllo A. Concepto y límites de la educación sanitaria escolar. Vida Escolar. 1961;26:2-8.

84. Maíllo A. Antropología de las comarcas subdesarrolladas y educación fundamental. En: La educación en la sociedad de nuestro tiempo. Madrid: Editorial Escuela Española; 1961. p. 247-264

85. Mainer Baque J, Mateos Montero J. Saber, poder y servicio: Un pedagogo orgánico del Estado: Adolfo Maíllo. Valencia: Tirant lo Blanc; 2011.

86. Maíllo A. Educacion popular y teleclubs. En: Cultura y educación popular. Madrid: Editora Nacional; 1967. p. 289-331.

87. Trescastro-López EM, Bernabeu-Mestre J, Galiana-Sánchez ME. Nutrición y salud pública: políticas de alimentación escolar en la España contemporánea (1931-1978). Asclepio. 2013;65(2):26

88. Trescastro López EM, Trescastro López S. La educación en alimentación y nutrición en el medio escolar: el ejemplo del Programa EDALNU. Revista Española de Nutrición Humana y Dietética. 2013;17(2):84-90.

89. Comelles JM, Perdiguero-Gil E. Las resistencias al Seguro Obligatorio de Enfermedad (1942-1967): la perspectiva de profesionales, trabajadores y ciudadanos. IX Encuentro de Investigadores del Franquismo: 80 años de la Guerra Civil Española; 10 y 11 de marzo de 2016; Granada, España.

90. De Miguel JM. La sociedad enferma: Las bases sociales de la política sanitaria española. Madrid: Akal; 1979. 
91. Comelles JM. De Girón de Velasco a Lluch: La constitución del modelo anglo-cubano-falangista de Seguridad Social en España. En: Campos R, Montiel L, Huertas R, (eds.). Medicina, ideología e historia en España (siglos XVI-XXI). Madrid: Consejo Superior de Investigaciones Científica; 2007. p. 377-388.

92. Perdiguero-Gil E, Martínez-Hernáez Á, Comelles JM. Medical anthropology in Spain: A historical perspective. Jahrbuch fur Europaische Ethnologie. 2014;9:216-249.

93. Bartoli P. Antropología en la educación sanitaria. Arxiu d'Etnografia de Catalunya. 1989;7: 17-24.

94. Gobierno de Aragón. Sistema de asesoramiento y recursos en educación para la salud [Internet]. c2017 [citado 26 oct 2016]. Disponible en http://tinyurl.com//2ree3e.
95. Comelles JM, Martínez-Hernáez A. Enfermedad, cultura y sociedad: Un ensayo sobre las relaciones entre la antropología social y la medicina. Madrid: EUDEMA; 1993.

96. Conti MJ. Enfermería y antropología: la literatura internacional. En: Comelles JM, Martorell MA, Bernal M. Enfermería y antropología: Padeceres, cuidadores y cuidados. Barcelona: Icaria; 2009. p. 219-234.

97. Casadó L. Antropología y enfermería: Revisión teórica y expectativas. En: Comelles JM, Martorell MA, Bernal M. Enfermería y antropología: Padeceres, cuidadores y cuidados. Barcelona: Icaria; 2009. p. 235-245.

98. Lionetti R. Antropologia e professione infermeristiche. Brescia: Grafo Edizioni; 1987.

99. Seppilli A. Educazione sanitaria e salute publica. Sistema Salute. 2014;58(3):271-276.

\section{FORMA DE CITAR}

Comelles JM, Riccò I, Terrón Bañuelos A, Perdiguero-Gil E. Educación sanitaria y antropología médica en Europa: los casos de Italia y España. Salud Colectiva. 2017;13(2):171-198. doi: 10.18294/sc.2017.1196.

Recibido: 30 de octubre de 2016 | Versión final: 12 de enero de 2017 | Aprobado: 6 de febrero de 2017

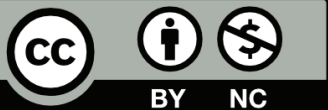

Este obra está bajo una licencia de Creative Commons Reconocimiento-NoComercial 4.0 Internacional. Reconocimiento - Permite copiar, distribuir y comunicar públicamente la obra. A cambio, se debe reconocer y citar al autor original. No Comercial - Esta obra no puede ser utilizada con finalidades comerciales, a menos que se obtenga el permiso.

http://dx.doi.org/10.18294/sc.2017.1196 